\section{Felipe}

Arévalo

\section{Cordero}

felipe.arevalo@ppulegal.com Recibido: 11.11.20 Aceptado: 01.09 .21

\title{
Debilidades del procedimiento sancionatorio ambiental y su control jurisdiccional relativas al aseguramiento del debido proceso
}

\section{Environmental sanctioning procedure weaknesses and its jurisdictional control regarding due process}

Resumen: El presente trabajo tiene por objeto dar una mirada panorámica al procedimiento sancionatorio ambiental y su control judicial desde la perspectiva del respeto a las garantías procesales de los administrados sometidos a la potestad sancionatoria de la Superintendencia del Medio Ambiente. Se analiza la siguiente pregunta: ¿entregan el sancionatorio ambiental y su control judicial elementos suficientes para la protección del debido proceso? La hipótesis que se esgrime es que, pese a que el procedimiento administrativo sancionador ambiental y su control judicial ha incorporado relevantes avances relativos al aseguramiento del debido proceso, siguen existiendo severas limitaciones tanto a nivel administrativo como judicial respecto a la protección de las garantías procesales de los administrados, carencias que se ven agravadas por la magnitud de las sanciones en la regulación ambiental.

Palabras clave: procedimiento sancionador; debido proceso; medio ambiente.
Abstract: The purpose of this work is to analyze the environmental sanctioning procedure and its judicial control from the perspective of the procedural guarantees of those subject to the Superintendence of the Environment's sanctioning powers. The following question is analyzed: Do the environmental sanction procedure and its judicial control provide enough elements to protect due process? Although the environmental sanctioning administrative procedure and its judicial control have incorporated relevant advances regarding the protection of a due process, they are still insufficient to guarantee the constitutional right of due process-deficiencies aggravated by the magnitude of the sanctions in the environmental regulation.

Keywords: sanctioning procedure; due process; environment. 
En la actualidad, resulta evidente la relevancia que tiene el medio ambiente para la subsistencia y el desarrollo de las personas y de la sociedad. Hace más de 40 años, la Constitución Política de la República de 1980 (en adelante CPR) reconoce como uno de los derechos fundamentales de las personas el de vivir en un medio ambiente libre de contaminación (artículo 19 № 8).

La concreción y aseguramiento de dicha garantía constitucional se materializó el año $1994^{1}$ con la promulgación de la Ley № 19.300 sobre Bases Generales del Medio Ambiente (en adelante LBGMA), cuerpo normativo que creó una serie de instrumentos de gestión ambiental, dentro de los que destacan las normas de calidad ambiental, las normas de emisión, los planes de prevención y descontaminación y el Sistema de Evaluación de Impacto Ambiental (en adelante SEIA).

Un segundo impulso relevante en la protección efectiva del medio ambiente, motivado sustantivamente por el interés de Chile de ingresar a la Organización para la Cooperación y Desarrollo Económico (en adelante OCDE)², se verificó el año 2010 con la entrada en vigor de la Ley № 20.417 que crea el Ministerio, el Servicio de Evaluación Ambiental y la Superintendencia del Medio Ambiente $^{3}$ (en adelante LOSMA), estableciendo la actual institucionalidad ambiental.

La protección efectiva del medio ambiente supone una serie de desafíos, destacando el necesario equilibrio que debe existir entre la referida protección al medio ambiente con el resto de las garantías constitucionales, particularmente con los derechos al debido proceso, a la libertad económica y a la propiedad (numerales $3^{\circ}, 21$ y 24 respectivamente del artículo 19 de la CPR).
Con la entrada en vigor de la LOSMA se estableció un nuevo procedimiento sancionatorio ambiental, que reemplazó a aquel contemplado originalmente en la LBGMA. La referida norma creó la Superintendencia del Medio Ambiente (en adelante SMA) otorgándole una serie de potestades relevantes para lograr la efectiva protección del medio ambiente, dentro de las que destaca la facultad de imponer sanciones de alta entidad respecto de incumplimientos detectados dentro de la esfera de su competencia.

De la lectura de la LOSMA, particularmente del Título III "De las Infracciones y Sanciones", resulta evidente que este procedimiento sancionatorio supone un gran avance tanto para la protección efectiva del medio ambiente como para el aseguramiento de los derechos individuales de los ciudadanos, particularmente la del derecho al debido proceso. Así "la sola existencia de una adecuada densidad normativa en la que se contengan las normas procedimentales mínimas es constitutiva de un límite al ejercicio de la potestad sancionadora y, por ende, es una garantía" (Bermúdez, 2013, p. 437) tanto en relación con el cumplimiento de la normativa vigente como de la protección de los derechos subjetivos de las personas (Bermúdez, 2013, p. 437).

Sin perjuicio de lo anterior, pese a ser en la actualidad uno de los procedimientos sancionatorios más sofisticados y desarrollados en el derecho administrativo nacional, sigue presentando una serie de carencias desde la perspectiva del debido proceso.

Por su parte, la Ley $N^{\circ} 20.600$ que crea los tribunales ambientales $^{4}$ (en adelante LTA), fruto de un acuerdo

\footnotetext{
${ }^{1}$ De manera paralela a la tramitación legislativa de la LBGMA el año 1992, en el marco de Asamblea General de la Naciones Unidas durante la Cumbre de Río de Janeiro, se efectuó la Declaración de Río sobre Medio Ambiente y el Desarrollo, la que establece en su Principio 11 que "Los Estados deberán promulgar leyes eficaces sobre el medio ambiente. Las normas, los objetivos de ordenación y las prioridades ambientales deberían reflejar el contexto ambiental y de desarrollo al que se aplican. Las normas aplicadas por algunos países pueden resultar inadecuadas y representar un costo social y económico injustificado para otros países, en particular los países en desarrollo".

2 Historia de la Ley No 19.300, Mensaje Presidencial, p. 4.

${ }^{3}$ Respecto a la creación de una entidad dedicada exclusivamente a la fiscalización y sanción en materia ambiental, el Informe de Desempeño Ambiental de Chile elaborado por la OCDE (2005) sugirió: "examinar formas de fortalecer la capacidad de cumplimiento y fiscalización, incluso mediante reformas institucionales, como por ejemplo el establecimiento de un órgano de inspección ambiental”.

${ }^{4}$ La LTA creó tres tribunales ambientales, con asiento en las ciudades de Santiago $\left(2^{\circ}\right)$, Valdivia $\left(3^{\circ}\right)$ y Antofagasta $\left(1^{\circ}\right)$. Iniciaron su función jurisdiccional el 28 de diciembre de 2012, el 9 de diciembre de 2013 y el 29 de junio de 2017 respectivamente.
} 
político ${ }^{5}$ estableció esta judicatura especial con la finalidad de actuar como órgano de control jurisdiccional de las decisiones de la $\mathrm{SMA}^{6} \mathrm{y}$, de esta forma, de resolver las controversias contenciosas administrativas que surgieran en el orden ambiental. Además, se facultó al tribunal (entre otras competencias) para resolver las demandas por daño ambiental ${ }^{7}$.

Este contencioso administrativo fue configurado por el legislador como uno de revisión y no de plena jurisdicción, lo que, sumado a las características del procedimiento sancionador ambiental, genera una serie de falencias respecto al debido proceso al que tienen derecho los regulados.

La tesis que se trata de defender en el presente trabajo es que, considerando las debilidades del procedimiento sancionatorio ambiental relativas al derecho al debido proceso, el contencioso administrativo ambiental, en particular el referido a la revisión jurisdiccional de las sanciones impuestas por la SMA, no logra asegurar adecuadamente la protección del referido derecho, el que se encuentra recogido fundamentalmente en el artículo $19 \mathrm{~N}^{\circ} 3$ de la CPR al establecer el derecho a un racional y justo procedimiento ${ }^{8}$.

Para intentar dar respuesta a la hipótesis formulada se buscará desarrollar el siguiente camino: (1.) explicar la interrelación existente entre la necesidad de protección urgente o inmediata del medio ambiente y el respeto al derecho al debido proceso, luego, (2.) describir y analizar el procedimiento sancionatorio ambiental, a continuación, (3.) desarrollar los aspectos del procedimiento que pueden ser considerados con distorsionadores del debido proceso, posteriormente, (4.) una descripción del contencioso administrativo ambiental y sus limitaciones a la luz del debido proceso, para finalizar con las (5.) conclusiones.

\section{Protección al medio ambiente y su vinculación con el debido proceso}

Desde un buen tiempo a esta parte, el medio ambiente ha sido considerado como un objeto jurídico en sí mismo ${ }^{9}$ que exige una protección directa e independiente del amparo de otros bienes jurídicos tradicionales (como la vida y la salud de las personas). Por su parte, atendiendo a las características particulares de dicho bien jurídico ${ }^{10}$, resulta especialmente relevante que el ordenamiento jurídico disponga de herramientas ágiles y versátiles para lograr su protección efectiva.

\footnotetext{
${ }^{5}$ Un antecedente al respecto corresponde al "Protocolo de Acuerdo de la Nueva Institucionalidad Ambiental" de fecha 26 de octubre de 2009 suscrito entre miembros del Senado y el Ejecutivo, protocolo que fue en definitiva materializado en el proyecto de ley ingresado a tramitación legislativa el 28 de octubre de 2009 № Boletín 6747-12.

${ }^{6}$ Al respecto señala Bordalí "La idea fundamental era balancear este poder de la Administración del Estado en materia ambiental con un tribunal de justicia de la más alta entidad y con atribuciones para controlar esa administración y para autorizar o ratificar en algunos casos sus actuaciones. De esta manera a un Estado regulador y sancionador más poderoso se le contrapone un tribunal imparcial de carácter técnico, colegiado, con jueces altamente calificados y bien remunerados" (Bordalí, 2014b, p. 335).

${ }^{7}$ Historia de la Ley № 20.600, Mensaje Presidencial, p.4

${ }^{8}$ Lo anterior, complementado con las exigencias de legalidad, tipicidad, irretroactividad, culpabilidad, proporcionalidad y presunción de inocencia (esta última sin reconocimiento expreso) de la referida garantía constitucional.

${ }^{9}$ Ver Gutiérrez, 1999, p. 344.

${ }^{10}$ De la mera lectura de la definición de medio ambiente contenida en el artículo $2^{\circ}$ letra II) de la LBGMA puede identificarse la naturaleza compleja, dinámica, interdisciplinaria y multifacética de este: "Artículo $2^{\circ}$ Para todos los efectos legales se entenderá por II) Medio Ambiente: el sistema global constituido por elementos naturales y artificiales de naturaleza física, química o biológica, socioculturales y sus interacciones, en permanente modificación por la acción humana o natural y que rige y condiciona la existencia y desarrollo de la vida en sus múltiples manifestaciones".
} 
En este sentido, la protección judicial tradicional (con la honrosa excepción del recurso de protección) en muchos casos no resulta suficiente para asegurar el cuidado al medio ambiente, ya que es bastante claro que "entre el inicio de la relación procesal y el cumplimiento de la sentencia definitiva, pueden ocurrir varias alteraciones jurídicas o de hecho, que terminen frustrando la pretensión del actor, y la falta de eficacia que se constata en la utilización de los diversos procedimientos, [lo que] ha intentado solucionarse buscando distintas fórmulas, que tienen como objetivo común enfrentar la demora del proceso" (Aguirrezabal, 2016, p. 26).

También debe considerarse que la protección del medio ambiente importa una de las limitaciones que acepta la propiedad privada ${ }^{11}$ y la libertad económica ${ }^{12}$, la que debe siempre ser equilibrada con la necesidad de asegurar un adecuado desarrollo económico. En este sentido "la estabilidad y certeza jurídica en los actos administrativos firmes en derecho ambiental es un pilar básico de la delicada ecuación que debe existir entre inversión privada, regulación y desarrollo sustentable" (Fermandois, 2005, p. 11).

Desde una perspectiva preventiva, atendiendo la relevancia que supone la protección del medio ambiente, el legislador condicionó el desarrollo de ciertas actividades predefinidas a la obtención previa de una autorización ambiental de funcionamiento ${ }^{13}$. En materia ambiental, la autorización de funcionamiento basal o matriz corresponde a aquella obtenida por medio de la evaluación ambiental previa del proyecto o actividad en el SEIA ${ }^{14}$, denominada Resolución de Calificación Ambiental (en adelante RCA). Esta autorización de funcionamiento "posee la aptitud de regular en el tiempo el desarrollo de una actividad, y en donde la producción de sus efectos se despliega en el tiempo en paralelo a la permanencia del acto en el mundo jurídico" (Sepúlveda, 2019, p. 13).

Por su parte, desde una perspectiva cautelar, la LOSMA faculta a la SMA para suspender transitoriamente las autorizaciones de funcionamiento contenidas en una RCA o adoptar otras medidas urgentes y transitorias para el resguardo del medio ambiente cuando la actividad genere daño grave e inminente para el medio ambiente (artículo $3^{\circ}$ letra g) o cuando la ejecución u operación de un proyecto evaluado ambientalmente genere efectos no previstos en su RCA (artículo $3^{\circ}$ letra g). Por su parte, el artículo 48 de la LOSMA entrega al Superintendente del Medio Ambiente la facultad de adoptar medidas provisionales $^{15}$ y proporcionales para evitar un daño inminente al medio ambiente. A su vez, el artículo 24 de la LTA faculta a los tribunales ambientales para decretar las medidas cautelares necesarias, conservativas 0 innovativas, para impedir los efectos de los actos o conductas sometidos a su conocimiento, pudiendo decretarlas incluso antes de iniciado el juicio.

Habiendo establecido lo anterior, resulta razonable sostener que la protección efectiva del medio ambiente, la que en muchos casos requiere una respuesta inmediata por parte del Estado como las recién explicadas,

\footnotetext{
${ }^{11}$ Al respecto, el artículo $19 N^{\circ} 24$ inciso segundo de la CPR dispone que "[s]olo la ley puede establecer el modo de adquirir la propiedad, de usar, gozar o disponer de ella y las limitaciones y obligaciones que deriven de su función social. Esta comprende cuanto exijan los intereses generales de la Nación, la seguridad nacional, la utilidad y la salubridad públicas y la conservación del patrimonio ambiental”.

12 El referido derecho se encuentra consagrado en el artículo $19 \mathrm{~N}^{\circ} 21$ de la CPR, en el que se establece como uno de sus límites el respeto a las normas legales que la regulen.

${ }^{13}$ El artículo 10 de la LGBMA establece un listado amplio de industrias y actividades que requieren contar con una evaluación ambiental favorable previo a su ejecución. De su lectura, puede comprobarse que se comprenden en él casi todas las actividades productivas relevantes desarrolladas en Chile (a modo de ejemplo: minería, energía, agroindustria, piscicultura, obras públicas de transporte, desarrollos inmobiliarios, entre otros).

${ }^{14}$ Con más de 20 años de funcionamiento del SEIA, durante los últimos años, estas autorizaciones de funcionamiento han alcanzado un estado de "hiperregulación" normativa, lo que evidentemente expone a sus titulares a una cantidad, muchas veces, inabordable de obligaciones "ambientales".

${ }^{15}$ La medida provisional ha sido conceptualizada por Arancibia como aquella "potestad imperativa que tiene por objeto poner fin al perjuicio del interés social, de modo transitorio, en espera de que el asunto sea decidido definitivamente, conforme a un debido proceso, por un órgano administrativo o jurisdiccional” (Arancibia, 2014, p. 141).
} 
no debiese alterar en nada la posibilidad (y garantía constitucional) del administrado de contar con un debido proceso (administrativo y judicial) para el aseguramiento de sus derechos. Así, en muchos casos, el interés de proteger el medio ambiente o alguno de sus componentes sugerirá la conveniencia de imponer medidas inmediatas para su cuidado (como las previamente descritas), lo que no obsta para la existencia de una revisión judicial lata y plena posterior.

Buscar una cabal protección del debido proceso no debe conducir al error de entender a la Administración o a la regulación administrativa que busca dar cumplimiento al interés social de proteger el medio ambiente como un impedimento o traba para el desarrollo de las actividades privadas, sino como un "instrumento positivo de regulación y configuración sociales, de aseguramiento de las condiciones básicas de la vida en colectividad" (Parejo, 2008, p. 82). Sin embargo, en el ejercicio de tan loable fin, debe en todo y cada caso específico respetarse las garantías constitucionales de cada persona, lo que obliga a implementar estándares de funcionamiento altos y mecanismos de control eficaces.

En este sentido, cobra relevancia la presunción de legalidad de los actos administrativos, la que conlleva el imperio del acto, es decir, la posibilidad de imponerlo ${ }^{16}$, no correspondiendo la referida presunción a "una institución que concierna a la razón de las cosas, sino que a la fuerza de aplicación de dichas cosas" (Bocksang, 2011, p. 226), es decir, no alcanza la base fáctica del acto, solo habilita a la Administración para cumplir eficientemente sus obligaciones haciendo exigibles sus mandatos.

Ahora bien, la existencia de un control judicial posterior no exime a la Administración de seguir un procedimiento administrativo racional y justo, tal como lo ha establecido el Tribunal Constitucional al disponer que "el derecho a defensa jurídica debe poder ejercerse, en plenitud, en todos y cada uno de los estadios en que se desarrolle el procedimiento, en los cuales se podrán ir consolidando situaciones jurídicas muchas veces irreversibles"17.

Enfrentado un individuo a persecución estatal por medio de una agencia determinada, en este caso la SMA, se encuentra evidentemente en una situación desmejorada, motivo por el cual, pareciera conveniente que todo el procedimiento sancionatorio, en particular los elementos probatorios, sean revisados latamente en la instancia judicial pertinente. Esta fue precisamente una de las razones que motivó la creación de los tribunales ambientales.

El referido desequilibrio entre la Administración y el destinatario de su actuar sería propio y connatural a la fase administrativa sancionadora y solo se equilibrará cuando el conflicto sea conocido en sede judicial. En este sentido, Jara señala que "en el campo del procedimiento administrativo de aplicación de sanciones, la naturaleza de la función gubernativa impone un desequilibrio en la posición entre el órgano administrativo y el interesado, derivada de los privilegios de autotutela decisoria y de los atributos de la presunción de legalidad, imperio y exigibilidad que benefician a sus actuaciones, en la esfera procesal, como acertadamente se ha expresado, el proceso judicial impone el quiebre de dicha desigualdad la que se reequilibra" (Jara, 2018, p 67).

Lo anterior, cobra particular relevancia en el caso de la imposición de sanciones de alta entidad, como la revocación de la licencia ambiental de funcionamiento (RCA), la clausura o cierre de establecimientos industriales, la imposición de multas millonarias o la identificación administrativa de posibles daños ambientales con motivo de la infracción imputada, las que deberían someterse a un control judicial mucho más pleno y amplio que la mera revisión de legalidad contemplada actualmente en la LOSMA y la LTA.

\footnotetext{
${ }^{16}$ Cabe resaltar que en materia ambiental, existe una excepción a esta regla general, consistente en la inexigibilidad de la multa mientras no venza el plazo para reclamar o hasta que la reclamación respectiva no haya sido resuelta (artículo 56 inc. $2^{\circ}$ de la LOSMA).

17 STC Rol No 376 de 2013. En el mismo sentido ver STC Rol № 389 de 2013.
} 


\section{Procedimiento sancionatorio ambiental}

\subsection{Potestad sancionatoria}

Enmarcada dentro de las actividades de policía ${ }^{18}$ que ejerce la Administración, la potestad sancionatoria puede ser entendida como el "poder jurídico con que cuenta la Administración del Estado, de carácter permanente, expresamente atribuido por ley, en virtud del cual se le habilita para perseguir al sujeto imputado de aquellas conductas activas u omisivas, que se estiman son constitutivas de infracción administrativa e imponerle una retribución negativa o sanción por las mismas" (Bermúdez, 2011, p. 273).

La referida potestad presenta como supuestos básicos de procedencia, además de la materialización a través de un procedimiento administrativo sancionador ${ }^{19}$, la existencia de una infracción y su sanción asociada, siendo la primera una conducta tipificada que por su concreción por parte del infractor tiene atribuida o atada una sanción, y la segunda, aquel mal infringido por la Administración que supone una conducta ilícita por parte del particular y una finalidad esencialmente represora (Cordero, 2014, p. 401).

Respecto a la justificación dogmática de la potestad sancionatoria se han desarrollado básicamente dos teorías: (i) aquella que la enmarca dentro del ius puniendi del Estado 20 y, por tanto, sujeta (aunque de manera matizada ${ }^{21}$ ) a los principios y garantías del derecho penal y (ii) aquella que la considera una expresión propia del derecho administrativo ${ }^{22}$, rama del derecho que no tiene por finalidad única entregar garantías al administrado, sino también tutelar el interés general de la sociedad (Román, 2008, p.107).

Refiriéndose al poder punitivo del Estado, Parejo comenta que "en efecto, ambas potestades (la punitiva judicial y la sancionatoria administrativa) tienen un núcleo propio, girando la penal en torno a la retribución por la lesión de bienes capaces de justificar la restricción de la libertad personal y la administrativa a la mera corrección de comportamientos que comprometen la efectividad de los fines y objetivos de la programación administrativa de políticas públicas" (Parejo, 2014, p.19).

Sin perjuicio de la justificación dogmática que se siga en el caso específico de la potestad sancionatoria ambiental, esta puede ser entendida como aquella potestad que el ordenamiento jurídico confiere a la SMA para "sancionar la infracción de una norma u acto vinculado a un instrumento de gestión ambiental, con miras a cumplir con los fines generales que no son otros que la protección y conservación del medio ambiente" (Hunter, 2020b, p. 98).

\footnotetext{
18 También conceptualiza por la doctrina como aquella actividad administrativa de limitación, toda vez que se manifiesta en una restricción o limitación del patrimonio o libertad de los administrados, limitaciones que siempre encuentran como límite la ley, el control jurisdiccional y la proporcionalidad (Bermúdez, 2011, p. 270).

${ }_{19}$ Al respecto, el Tribunal Constitucional en sentencia de la causa Rol N 1413-2010 dispuso que "es imprescindible que la ley prevea un debido proceso para la aplicación de las sanciones".

${ }^{20}$ Ver Bermúdez (2013) p. 427 y Cordero (2014) p. 402.

${ }^{21}$ Esta correspondería a la tesis aceptada mayoritariamente en la doctrina nacional. En este sentido, la Corte Suprema ha dispuesto que "tanto la sanción penal como la administrativa, son manifestaciones de un único ius puniendi estatal... Sin embargo, ello no importa de inmediato la aplicación de los principios del derecho penal a la sanción impuesta por la Administración, por cuanto existen ciertos matices dados principalmente por la finalidad perseguida por el legislador al asociar uno u otro tipo de responsabilidad a una conducta determinada" SCS Rol №17.736-2016, Considerando $18^{\circ}$.

22 Tesis sostenida y defendida principalmente por Nieto, entre otros. Ver Nieto (2014).
} 
2.2. Concepto, objetivo y determinación de las sanciones

Para Bermúdez, la sanción administrativa corresponde a aquella retribución negativa prevista en el ordenamiento jurídico e impuesta por una Administración Pública por la comisión de una infracción administrativa (Bermúdez, 2011, p. 326), participando de este carácter, entre otros, la amonestación, multa, cierre o clausura, la revocación de una autorización o permiso.

En opinión de Alcalde, la sanción administrativa debe ser entendida como una pena vinculada a la comisión de un hecho típico y antijurídico impuesta por la Administración al sujeto a quien resulte responsable, siempre con sujeción a las limitaciones a que se encuentra sometido el ejercicio del ius puniendi estatal (Alcalde, 2009, p. 796).

Respecto a su procedencia, atendiendo el principio de necesidad solo procedería su aplicación como una alternativa de ultima ratio, es decir, que "solo sería necesaria, y por ende justa, en caso de ineficacia o insuficiencia de las medidas correctivas de que dispone la Administración Pública para tutelar el interés público" (Arancibia, 2014, p. 13). Lo anterior, supone que "la sanción sea concebida y ponderada como un instrumento de carácter administrativo y, como tal, alternativo y residual en el fin de prevenir y enmendar faltas al ordenamiento jurídico" (Arancibia, 2014, p. 134).

En el ejercicio de su potestad sancionatoria, la Administración cuenta con una batería o catálogo de sanciones ${ }^{23}$, las que pueden expresarse de distinta manera. Así, podemos identificar típicamente la multa, entendiendo por tal la condena pecuniaria que se le impone a un infractor, las suspensiones, limitaciones, privaciones de un derecho y la revocación sancionatoria de ciertos títulos administrativos que autorizan el desarrollo de ciertas actividades (Bermúdez, 2013, p. 427).

Excepcionalmente, ciertas sanciones escapan de la cotidianeidad y de la mera ejecución de una regulación y pasan a ser realmente retribuciones de un mal por ciertas situaciones, lo que las convierte en una categoría (o subcategoría de las sanciones) que debiese aceptar la procedencia de un mayor estándar probatorio y de un control judicial más completo o pleno.

Algunas delasalternativassancionatoriascontempladas en la normativa ambiental chilena se escapan, en nuestra opinión, de la mera corrección regulatoria, y se configuran más bien como penas propiamente tales. En este caso se encontrarían la revocación de la RCA, la clausura o cierre, permanente o temporal de establecimientos y las multas de alta cuantía ${ }^{24}$.

En opinión de Letelier, "si algo caracteriza la potestad administrativa sancionatoria -al menos en este tipo de casos - es que ella se alinea exclusivamente con la faz preventiva y disuasoria de los fines de toda sanción. Su objetivo en caso alguno es generar un castigo al infractor como forma de retribución de su mal, sino simplemente hacer coercible, aplicable, ejecutable un estándar de comportamiento administrativo, aportando razones para la acción futura de aquellos a quienes afectan los deberes de ese estándar" (Letelier, 2018, p. 223).

La doctrina ya ha advertido sobre los riesgos asociados a la entrega de grandes potestades sancionatorias a la Administración y la necesidad de que aquellas sean ejercidas siempre en cumplimiento de las garantías procesales del debido proceso. De esta forma, "Los abusos a que tales medidas - sanciones administrativas - pueden conducir, explica los graves

\footnotetext{
${ }^{23}$ La regla general es que las sanciones sean consideradas como una técnica o herramienta de enforcement o aplicación de la regulación administrativa.

${ }^{24}$ Conforme a lo dispuesto en el artículo 38 de la LOSMA, las infracciones ambientales pueden ser sancionadas, cada una, con una amonestación, una multa (de hasta 10.000 Unidades Tributarias Anuales), la clausura temporal o definitiva de las instalaciones y la revocación de la RCA.
} 
reparos que suscita su utilización, sobre todo cuando ella quebranta los criterios de respeto de la dignidad y de los derechos fundamentales de la persona que deben servir de freno a los excesos del poder político"25. Sin embargo, "si se quiere realmente un auténtico Estado de Derecho democrático, la aplicación de esas facultades - limitada a los casos permitidos por la Constitucióndeberá responder de una necesidad ineludible y sujetarse a los criterios de moderación, proporcionalidad y subsidiariedad"26.

Desde otra perspectiva, pero muy vinculado también con la necesidad de obtener un control judicial pleno que incluya la revisión de la base fáctica sobre la que se fundamenta la decisión administrativa, se encuentran ciertas afirmaciones o declaraciones que se incorporan habitualmente dentro de una sanción administrativa ambiental. Dentro de ellas resultan particularmente relevante aquellas vinculadas a la "declaración" de la existencia de un "daño ambiental"27.

\subsection{Procedimiento sancionatorio ambiental}

El procedimiento sancionatorio ambiental se encuentra regulado en la LOSMA, particularmente en su Título III en los artículos 35 a 57, con aplicación supletoria de la Ley $N^{\circ} 19.880$ que establece Bases de los Procedimientos Administrativos que Rigen los Actos de los Órganos de la Administración del Estado (en adelante "LBPA") según lo dispone el artículo 62 de la LOSMA.

En este procedimiento administrativo, la SMA debe seguir un camino lógico partiendo por la configuración de la o las infracciones imputadas al supuesto infractor materializada en la formulación de cargos (artículo 49 inc. Final), la clasificación de la gravedad de estas (artículo $36^{28}$ ) y la determinación del tipo de sanción (artículo $38^{29}$ ) y la entidad de la sanción que imponer (artículo 4030).

El procedimiento puede iniciarse de oficio, por petición de un órgano sectorial o por denuncia (artículo 47), lo que gatillará ciertas actividades de fiscalización, investigación y constatación de los hechos denunciados. El procedimiento, luego, será sustanciado por un fiscal instructor (artículo 48), iniciando con una formulación de cargos. Respecto de ésta, el sujeto regulado tiene la posibilidad de presentar descargos o un programa de cumplimiento.

Respecto a la prueba, en este procedimiento se acepta cualquier medio de prueba admisible en derecho, los que serán apreciados conforme a las reglas de la sana crítica (artículo 51).

Una vez determinada la infracción, deberán considerarse ciertos criterios de graduación y ponderación de sanciones, que en general se derivan del principio de proporcionalidad, que es fundamental del Derecho administrativo sancionador. Conforme a él se permite adecuar la represión a la infracción y sus circunstancias, limitando la discrecionalidad administrativa en su imposición" (Bermúdez, 2014, p. 480).

Concluidas las medidas o diligencias probatorias, el fiscal instructor del procedimiento debe emitir un dictamen proponiendo la absolución del fiscalizado o la

\footnotetext{
${ }^{25}$ Politoff, S. (2001). Derecho Penal. Santiago: Editorial Conosur, pp. 37-38, citado en Román (2008), p.115.

${ }^{26}$ Politoff (2001), pp. 37-38, citado en Román (2008), p. 115.

${ }^{27}$ Un mayor desarrollo de esta idea puede ser consultada en Arévalo y Mozó (2017).

${ }^{28}$ El artículo 36 de la LOSMA establece un listado de causales de calificación de gravedad de sanciones, pudiendo ser estas leves, graves o gravísimas. El referido artículo desarrolla los criterios en virtud de los cuales se deberá determinar la calificación de gravedad de la sanción.

${ }^{29}$ Las sanciones pueden ser (i) amonestación por escrito, (ii) multa de 1 a 10.000 Unidades Tributarias Anuales, (iii) clausura temporal o definitiva de instalaciones y (iv) revocación de la RCA.

${ }^{30}$ El Artículo 40 de la LOSMA identifica como criterios para determinar las sanciones específicas (i) la importancia del daño causado o peligro ocasionado, (ii) el número de personas que pudieran haber visto afectada su salud, (iii) el beneficio económico obtenido por el infractor con motivo de la infracción, (iv) la intencionalidad del infractor, (v) la conducta anterior del infractor, (vi) la capacidad económica del infractor, (vii) el cumplimiento de un programa de cumplimiento, (viii) la afectación de un área silvestre protegida y (ix) otros criterios que en opinión de la SMA sean procedentes.
} 
imposición de la sanción que estime pertinente (artículo 53). El dictamen es elevado al Superintendente del Medio Ambiente quien resolverá ${ }^{31}$ mediante una resolución fundada (artículo 54).

Respecto a la posibilidad de impugnar la sanción impuesta por la SMA procederá el recurso de reposición dentro del plazo de cinco días (artículo 55) y el recurso de reclamación ante el tribunal ambiental competente dentro del plazo de 15 días (artículo 56).

\subsection{Avances en la protección del debido proceso incorporados por la LOSMA}

Resultaría injusto (e incorrecto) afirmar que la LOSMA no ha dado pasos significativos en orden a tutelar las garantías procesales de los fiscalizados. En este sentido, dentro del procedimiento sancionatorio ambiental (latamente regulado por el legislador) pueden identificarse los siguientes aspectos:

\subsubsection{El establecimiento explícito ${ }^{32}$ de la necesidad} de realizar una formulación de cargos en el inicio del procedimiento33: el que debe contener una "descripción clara y precisa de los hechos que se estimen constitutivos de infracción y la fecha de su verificación, la norma, medidas o condiciones eventualmente infringidas $y$ la disposición que establece la infracción, y la sanción asignada y su respectiva notificación" (artículo 49), permitiendo al supuesto infractor saber en detalle de qué se le está acusando, la norma infringida y la posible sanción aplicable.

Aparejado a lo anterior, el artículo 54 en su inciso final establece un deber de coherencia ${ }^{34}$ a la SMA al disponer que "ninguna persona podrá ser sancionada por los hechos que no hubiesen sido materia de cargos". Pese a no señalarlo explícitamente, parece razonable incluir dentro de este deber de coherencia el fundar la sanción en las mismas normas jurídicas imputadas.

\subsubsection{Desde una perspectiva orgánica: se establece} (i) la separación de las funciones de investigación e instrucción ${ }^{35}$, contenida en el artículo $7^{\circ}$ inciso segundo ${ }^{36}$, lo que se materializa en la designación de un fiscal instructor, distinto e independiente del o los funcionarios que realizaron la correspondiente fiscalización (artículo 49) y (ii) la separación de funciones de instrucción del procedimiento sancionatorio y la potestad sancionatoria, terminando la intervención del fiscal instructor con la emisión de su dictamen (artículo 53) el que sugerirá la absolución o sanción del infractor, radicando

\footnotetext{
${ }^{31}$ El Superintendente se encuentra facultado para, antes de resolver, decretar la realización de nuevas diligencias y/o la corrección de vicios procedimentales (artículo 54 inc. $2^{\circ}$ de la LOSMA).

${ }^{32}$ Respecto a aquellos procedimientos en los que la ley no exige explícitamente la formulación de cargos, la Corte Suprema a dispuesto que "se debe exigir únicamente que se ponga en conocimiento del administrado que se está llevando a cabo una investigación por determinados hechos los que eventualmente podrían ser constitutivos de infracciones precisas indicándose al efecto las normas legales que se estiman infringidas, entregando la oportunidad de esgrimir defensas que se estimen necesarias como asimismo la de rendir la prueba pertinente". SCS Rol N 177-2017, Considerando $15^{\circ}$.

${ }^{33}$ Este avance contrasta con otros procedimientos sancionatorios en los que la formulación de cargos no aparece expresamente recogida como un trámite esencial del procedimiento. A modo de ejemplo, en el sumario sanitario conforme al artículo 163 del Código Sanitario, será el acta de fiscalización la que hará las veces de formulación de cargos.

${ }^{34}$ En relación con este deber de coherencia, la Corte Suprema a sentenciado que "de la sola lectura de los fundamentos del cargo formulado y de la resolución sancionatoria surge la evidencia que los hechos tenidos en vista para la adopción del acto administrativo son distintos de aquéllos anteriores a éste, de lo cual se deriva su ilegalidad. En materia de imposición de sanciones por parte de la Administración, ello adquiere especial trascendencia, toda vez que el derecho a la debida defensa exige a ésta una conducta congruente en cuento a los cargos que formula y los hechos por los cuales se sanciona, única forma en la que puede configurarse la tipicidad exigible en esta materia". Corte Suprema, Sentencia de 5 de mayo de 2016, Rol № 5120-2016.

${ }_{35}^{35}$ Diferenciación que encuentra su sustento remoto en el principio de imparcialidad contenido en el artículo 11 de la LBPA.

${ }^{36}$ Este elemento, en opinión de Bermúdez, resulta cuestionable como garantía procedimental considerando las amplias facultades con que cuenta el superintendente del Medio Ambiente para la ordenación interna de la SMA, por lo que "parece dificultoso que un funcionario que ejercer labores de fiscal instructor se aparte de los criterios e instrucciones que de manera formal o informalmente le dé el Superintendente cuando pesa sobre aquel la posibilidad de vacancia" (Bermúdez, 2013, p. 440).
} 
privativamente en el Superintendente la posibilidad de aplicar la sanción correspondiente (artículo 4 letra h) y 35 letra $n)^{37}$

2.4.3. En relación con el derecho de defensa: se establece (i) un plazo de 15 días hábiles para formular descargos ${ }^{38}$. Sin perjuicio de que desde una perspectiva objetiva parece un plazo razonable para defenderse, esta razonabilidad se ve fuertemente atenuada si se considera la complejidad habitual que presentan las infracciones en materia ambiental y el amplísimo plazo otorgado por el legislador a la SMA (3 años) ${ }^{39}$ para formular los cargos desde iniciado el proceso de investigación administrativo; (ii) la posibilidad de presentar los medios probatorios que se estimen procedentes y solicitar las medidas o diligencias probatorias $^{40}$ en la medida en que copulativamente se hayan solicitado en el escrito de descargos ${ }^{41}$, sean pertinentes (es decir, que estén relacionados con los hechos materia de los cargos) y conducentes (idóneos para aportar antecedentes relevantes para la decisión de la autoridad), aportación probatoria que puede vincularse tanto con la existencia de la infracción como respecto de cualquiera de las circunstancias de determinación de sanciones contenidas en el artículo 40 de la LOSMA ${ }^{42}$, y (iii) la determinación de un plazo de prescripción explícito de las infracciones de 3 años (artículo 37) ${ }^{43}$.

\subsubsection{Respecto a la imposición de sanciones: se} consagra (i) la radicación exclusiva en la SMA de la persecución sancionatoria ambiental (artículo 59 inc. $\left.1^{9}\right)^{44}$, obligando a los demás órganos de la Administración a inhibirse de iniciar otros procesos sancionatorios administrativos por los mismos hechos (artículo 59 inc. $2^{\circ}$ ); (ii) la existencia del trámite de consulta cuando la SMA impone ciertas medidas provisionales (contenidas en el artículo 48 literales c), d) y e) ${ }^{45}$ ); (iii) la consulta de la imposición de las sanciones de clausura temporal o definitiva de proyectos y la revocación de las RCA contempladas en el artículo 28 literales c) y d) (artículo 57 LOSMA), y (iv) la incorporación de criterios de determinación y gravedad de las sanciones que deben ser impuestas por la SMA (artículo 40) ${ }^{46}$.

\footnotetext{
${ }^{37}$ En opinión de Bermúdez, el artículo 35 letra n) de la LOSMA "debe entenderse como una atribución de competencia residual. Por ello, debió especificar la ausencia de competencias por parte de otro órgano y no el no establecimiento de una sanción. Toda disposición no anudada a un castigo no puede interpretarse en términos infraccionarios, como tampoco es posible concluir que esta disposición tipifique una infracción general respecto de un incumplimiento cualquiera de toda otra norma de carácter ambiental" (Bermúdez, 2013, p. 442).

${ }^{38} \mathrm{Sin}$ perjuicio de la posibilidad que le otorga la ley al supuesto infractor de presentar un programa de cumplimiento dentro de un plazo de 10 días hábiles desde la notificación de la formulación de cargo, el que de ser aprobado produce la suspensión del procedimiento sancionatorio (artículo 42).

${ }^{39}$ Plazo deducido del artículo 37 de la LOSMA que establece la prescripción de las infracciones: "Las infracciones previstas en esta ley prescribirán a los tres años de cometidas, plazo que se interrumpirá con la notificación de la formulación de cargos por los hechos constitutivos de las mismas".

${ }^{40}$ Al respecto el artículo 50 inciso segundo de la LOSMA establece que "En todo caso, se dará lugar a las medidas o diligencias probatorias que solicite el presunto infractor en sus descargos, que resulten pertinentes y conducentes. En caso contrario, las rechazará mediante resolución fundada".

${ }^{41}$ Al respecto en Sentencia del Segundo Tribunal Ambiental de 21 de septiembre de 2014, en causa Rol 24-2014 se resolvió en su considerando duodécimo que "para poder decidir sobre la procedencia de las medidas o diligencias probatorias, la Administración necesita conocer con precisión y claridad cuáles son esas diligencias o medios de prueba ofrecidos por el presunto infractor, de lo contrario, será imposible determinar su pertinencia". En el mismo sentido, ver SCS Rol № 9703-2012, de 20 de agosto de 2013.

42 Así lo ha afirmado el Segundo Tribunal Ambiental en causa Rol 6-2013 "Con todo, las diligencias probatorias que pueden solicitar las partes, no se agotan en aquellas destinadas a acreditar las infracciones, sino que además comprende a aquellas diligencias o antecedentes que permitan ilustrar respecto a los criterios contenidos en el artículo 40 de la LOSMA".

${ }^{43}$ Con este artículo se supera en materia ambiental la vieja y vigente discusión respecto a la elección de la normativa supletoria aplicable (Código Penal o Código Civil) frente a la ausencia de una definición de la prescripción de infracciones en los procedimientos administrativos sancionatorios.

${ }^{44}$ Al respecto ver dictámenes de la Contraloría General de la República № 57.823/2016 y № 25.081/2013.

45 Dichas medidas corresponden a la clausura temporal, parcial o total, de las instalaciones, la detención de funcionamiento de las instalaciones o la suspensión temporal de la resolución de calificación ambiental.

${ }^{46}$ En este sentido, resulta justo referir la proactividad y seriedad con que la SMA ha procurado realizar la mencionada decisión y ponderación del tipo y entidad de las sanciones que aplica. Dicha preocupación encuentra su máxima expresión en documento denominado "Bases Metodológicas para la determinación de Sanciones Ambientales” actualizada al mes de diciembre de 2017.
} 
2.4.5. El reconocimiento y regulación expresa del non bis in idem: disponiendo al efecto el artículo 60 inc. $2^{\circ}$ que "en ningún caso se podrá aplicar al infractor, por los mismos hechos y fundamentos jurídicos, dos o más sanciones administrativas". Desde una perspectiva sancionatoria administrativa, el non bis in idem puede ser entendido como el derecho de un ciudadano a no ser castigado dos veces por el mismo hecho con una pena administrativa o con dos sanciones administrativas, siendo irrelevante si estas se materializan de forma simultánea o sucesiva (Bermúdez, 2011, p. 288).

En relación con el típico problema de la determinación de la vía por la que se sancionará a un sujeto, el inciso $1^{\circ}$ del mismo artículo entrega una solución clara "cuando por unos mismos hechos y fundamentos jurídicos, el infractor pudiese ser sancionado con arreglo a esta ley y por otra u otras leyes, de las sanciones posibles, se le impondrá la de mayor gravedad".

Sin perjuicio de estos grandes avances respecto a la protección de las garantías procesales de los administrados, como se intentará demostrar en el siguiente acápite, persisten ciertas carencias o deficiencias relevantes para el aseguramiento del debido proceso.

\section{Elementos distorsionadores del debido proceso en el sancionatorio ambiental}

La CPR asegura a todas las personas el derecho a un "racional y justo procedimiento" (art. 19 № 3 inciso 6\%), garantía que debe ser entendida como el reconocimiento en nuestro ordenamiento del debido proceso como derecho fundamental de los ciudadanos (Bordalí, 2017, p. 291). Respecto a este reconocimiento constitucional, el Tribunal Constitucional ha establecido que pese a no contener una norma expresa que lo defina, la constitución regula dos elementos configurativos del debido proceso. "En primer lugar, que toda sentencia de un órgano que ejerza jurisdicción ha de fundarse en un proceso previo legalmente tramitado. En segundo lugar, que corresponderá al legislador establecer las garantías de un procedimiento racional y justo" ${ }^{\prime 7}$.
Este derecho al debido proceso debe ser entendido como una garantía que ampara al individuo en sus derechos subjetivos, configurando un mecanismo de protección frente a los actos administrativos que quebranten la ley, impidiendo que se genere un abuso de poder que pudiera afectar el derecho de las partes (Jara, 2018, p. 68).

La garantía del debido proceso no debe ser reducida al funcionamiento de los tribunales de justicia, debiendo ser resultando aplicable también a los procedimientos y administrativos ${ }^{48}$, lo que se desprende del artículo $19 \mathrm{~N}^{\circ}$ 3 inciso $6^{\circ}$ que dispone al efecto que "toda sentencia

\footnotetext{
47 Tribunal Constitucional en STC 821-2008, Considerando $8^{\circ}$. En el mismo sentido, STC 2702, Considerando 30, STC 2895, Considerando $3^{\circ}$ y STC 3029, Considerando $3^{\circ}$.

${ }^{48}$ Este criterio ha sido corroborado por el Tribunal Constitucional en STC 1518-2010, conociendo de un recurso de inaplicabilidad por inconstitucional en el marco de un sancionatorio sanitario que dispuso en su considerando $24^{\circ}$ que "con los matices que obedecen a las características propias del derecho administrativo sancionador, las garantías del debido proceso le son aplicables. En efecto, ha manifestado respecto al procedimiento administrativo sancionador que "no obstante, aunque se trate de potestades que no suponen ejercicio de jurisdicción, ciertamente deben sujetarse a los parámetros propios de un debido proceso". Adicionalmente, este Tribunal ha precisado que "Ios principios inspiradores del orden penal han de aplicarse, por regla general, al derecho administrativo sancionador, puesto que ambos son manifestaciones del ius puniendi" (sentencia rol № 244 , considerando noveno, y, más recientemente, en los autos rol No 480)".
} 
de un órgano que ejerza jurisdicción debe fundarse en un proceso previo legalmente tramitado. Corresponderá al legislador establecer siempre las garantías de un procedimiento e investigación racionales y justos".

Al respecto, es nutrida y consistente la jurisprudencia del Tribunal Constitucional que dispone que no obstante no ser potestad jurisdiccional, "la potestad para aplicar, rebajar o condonar sanciones administrativas debe sujetarse a los parámetros del debido proceso, puesto que los principios inspiradores del orden penal han de aplicarse, por regla general, al derecho administrativo sancionador, al ser ambas manifestaciones del ius puniendi. Principalmente será exigible el principio de legalidad, tipicidad y derecho a impugnarlo ante los Tribunales de Justicia ${ }^{49 " .}$

De este modo, si el constituyente optó por hablar de un "procedimiento racional y justo" sin acotarlo al procedimiento judicial "cabe entenderlo aplicable a todos los procedimientos de los órganos del Estado y no solo aquel que se desarrolla ante los tribunales de justicia" ${ }^{\text {. }}$.

En las siguientes líneas se desarrollarán las que, en nuestra opinión, corresponden a las principales carencias o debilidades del procedimiento sancionatorio ambiental a la luz del derecho al debido proceso.

3.1. Presunción de legalidad de los hechos constatados por funcionarios de la SMA

Enelmarco delsancionatorioambiental, tantoloshechos investigados como las potenciales responsabilidades de los administrados pueden acreditarse mediante cualquier medio de prueba admisible en derecho, los que se apreciarán de acuerdo con las reglas de la sana crítica (artículo 51 de la LOSMA).

Dentro de los medios de acreditación, la LOSMA les otorga un valor especial a los hechos establecidos por los funcionarios de la SMA en su condición de ministro de $\mathrm{fe}^{51}$, los que constando en un acta de fiscalización gozan de una presunción de legalidad conforme al artículo $8^{\circ}$ del mismo cuerpo normativo ${ }^{52}$ dada su condición de actos administrativos de constancia de acuerdo con el artículo $3^{\circ}$ de la LBPA.

Respecto al alcance de esta presunción, doctrinalmente se ha entendido que solo debe remitirse o acotarse a los hechos constatados directamente por el fiscalizador, y por hechos coetáneos al proceso y no pasados (Jara y Maturana, 2019, p. 19), debiendo además dársele un alcance restrictivo considerando que su finalidad se vincula con el aseguramiento de la eficacia de la actuación administrativa y no con el corresponder directamente a un mecanismo para facilitar su prueba en juicio (Hunter, 2016, p. 218).

En este sentido, resulta al menos cuestionable que un acta de fiscalización de un funcionario de la SMA (o de otro funcionario público realizando actividades de fiscalización ambiental por encargo de la SMA) tenga la entidad de desvirtuar o destruir por sí misma la presunción de inocencia del administrado, asignándole la LOSMA un valor privilegiado a dichas actas de fiscalización dentro de los medios de acreditación contemplados en la

\footnotetext{
${ }^{49}$ Tribunal Constitucional en STC 712-2008. En el mismo sentido STC 1518 Considerandos $6^{\circ}$ y $24^{\circ}$, STC 2264 Considerando $33^{\circ}$, STC 2682 Considerando $7^{\circ}$, STC 2784 Considerandos $11^{\circ}$ y $12^{\circ}$, y STC 3625 Considerando $33^{\circ}$ ).

50 STC 712-2008

${ }^{51}$ Respecto al alcance general que tienen las actas de fiscalización, la LBPA no le otorga una tratativa especial, por lo que la presunción de legalidad contenida en los artículos 51 y 8 de la LOSMA corresponde a una excepción dentro del ordenamiento jurídico (también goza de dicha categoría las actas de los sumarios sanitarios conforme al artículo 166 del Código Sanitario).

${ }^{52}$ En este sentido, resulta interesante tener a la vista lo señalado por la Corte Suprema en la causa Rol № 38.340-2016, en su Considerando 13: "los funcionarios de los organismos sectoriales que ostentan el carácter de ministros de fe en virtud de lo dispuesto en la ley que los rige, mantienen tal calidad en relación a materias vinculadas a instrumentos ambientales, sin que sea procedente realizar una distinción en relación al origen de la fiscalización, discriminando entre aquellas realizadas dentro de un subprograma, a requerimiento de la SMA o de forma independiente, toda vez que si la ley no distingue, no es lícito que el intérprete lo haga más aún cuando el tenor de aquella es claro".
} 
referida norma. Agrava lo anterior el hecho de que en muchas oportunidades dichas actas no son completas ni contienen toda la información requerida debiendo ser completadas por la misma autoridad con posterioridad y con desconocimiento por parte del fiscalizado.

Cabe considerar aquí que en opinión del Tribunal Constitucional ${ }^{53}$, conociendo de una cuestión sanitaria pero perfectamente extrapolable a materia ambiental, rige plenamente la presunción de inocencia en el marco del sancionatorio administrativo por lo que corresponde a la Administración desvirtuar tal presunción aportando prueba al efecto, con lo que recae en la autoridad la carga de la prueba.

Sin perjuicio de lo anterior, debe reconocerse todos los esfuerzos realizados sistemáticamente por parte de la SMA para obtener elementos probatorios de carácter técnico y objetivo para realizar sus formulaciones de cargos y posteriores determinaciones de sanciones, lo que no le quita su condición de prueba autogenerada lo que refuerza la necesidad de que sea revisada judicialmente.

3.2. La excesiva desproporción en los tiempos de preparación del caso por parte de la SMA y el tiempo para presentar descargos por parte del administrado.

Conforme lo dispuesto en el artículo 49 de la LOSMA, desde notificada la formulación de cargos al presunto infractor, este podrá presentar sus descargos dentro de un plazo de 15 días. Respecto a los descargos la jurisprudencia ha señalado que "el legislador ha establecido que la vía jurídica que tiene el administrado para defenderse, impugnando o contraviniendo la formulación o reformulación de cargos, es precisamente el escrito de descargos" ${ }^{\prime \prime}$.
Por su parte, la SMA, en la hipótesis de que, llevando a cabo sus actividades de fiscalización, identifique una posible infracción cuenta con un plazo de tres años para realizar la formulación de cargos, plazo que se infiere del ya mencionado artículo 37 de la LOSMA que establece la prescripción de las infracciones ${ }^{55}$.

Resulta bastante evidente que la posibilidad de acceder a elementos probatorios por parte del supuesto infractor por acciones que ejecutó tres años atrás se vuelve, a lo menos, una tarea compleja (si no imposible), situación que se ve acentuada por (i) la necesidad de acompañarlos al escrito de descargos dentro del plazo de 15 días ya referido y (ii) por el alto estándar técnico incorporados en los análisis de la SMA al momento de formular cargos.

En este sentido, reconociendo la posibilidad que tienen el fiscalizado de realizar las aportaciones que estime pertinentes dentro de la tramitación del procedimiento sancionatorio, no resulta menos cierto que es el escrito de descargos la instancia procedimental oportuna para acompañar los medios de prueba por parte del administrado y el momento en el que se deben solicitar las "medidas o diligencias probatorias", las que en todo caso solo se practicarán si en opinión motivada de la SMA resultan "pertinentes y conducentes" (artículo 50).

\subsection{Limitaciones de acceso al expediente de fiscalización}

Revisada la práctica administrativa de la SMA, puede constatarse quela información contenida en un expediente de fiscalización solo llega a conocimiento del fiscalizado una vez que se inicia el respectivo procedimiento sancionatorio. Este comportamiento ha sido avalado

53 STC Rol No 1518-2010, ver Considerandos $N^{\circ} 22^{\circ}$ a $25^{\circ}$ en materia sanitaria.

${ }^{54}$ STA2 $^{\circ}$, Rol R-122-2016, Considerando $37^{\circ}$.

${ }^{55}$ La referida norma dispone que "las infraccione previstas en esta ley prescribirán a los tres años de cometidas, plazo que se interrumpirá con la notificación de la formulación de cargos por los hechos constitutivos de las mismas". 
jurisprudencialmente por los tribunales ambientales, los que han sostenido que el derecho a conocer el expediente de fiscalización solo debe garantizarse desde el inicio del procedimiento sancionatorio ${ }^{56}$.

La imposibilidad de tener acceso al expediente de fiscalización llevado a cabo por la SMA mientras no se haya formulado cargos, resulta contrario con la lógica de la LOSMA que busca resguardar el respeto al debido proceso y, además, a lo establecido en la Ley № 20.285 sobre acceso a la información pública, específicamente a lo establecido en su Art. $21 \mathrm{~N}^{0} 1$ letra b) $)^{57}$.

El artículo $17 \mathrm{~N}^{\circ} 1$ letra a) de la LBPA consagra el derecho de quienes tengan la condición de interesados en un procedimiento administrativo a "obtener copia autorizada de los documentos que rolan en el expediente". En el mismo sentido, Cordero enseña que "las personas tendrán derecho a conocer, en cualquier momento, el estado de la tramitación de los procedimientos en los que tengan la condición de interesados, y obtener copia autorizada de los documentos que rolan en el expediente..." (Cordero, 2015a, p. 377).

En fallo de fecha 7 de agosto de 2017, en causa Rol $N^{\circ}$ $41.790-2016^{58}$, la Corte Suprema discurre sobre este asunto señalando en su considerando octavo que "En el caso de la Superintendencia del Medio Ambiente, la ley define como parte principal de su objeto el "ejecutar, organizar y coordinar el seguimiento y fiscalización de las Resoluciones de Calificación Ambiental”. Este objeto justifica una prerrogativa, aunque no ilimitada, a mantener reserva o secreto de información en cuanto ello sea necesario para el cumplimiento de dicho objeto.
Por otra parte, el fiscalizado tiene derecho a defenderse. Es efectivo, como alegó la Superintendencia en estrados, que tal derecho está reconocido por la legislación y se activa con la formulación de cargos. Pero la Corte no puede desconocer que ese derecho puede verse seriamente afectado si la Administración deja transcurrir un plazo excesivo entre la fiscalización y la formulación de cargos. En efecto, el paso del tiempo puede comprometer seriamente la capacidad del fiscalizado para producir prueba de descargo.

De esta manera, el máximo tribunal concluye que la prerrogativa que asiste a la Administración no puede traducirse en un perjuicio en contra de los administrados, la invocación del mentado artículo $21 \mathrm{~N}^{\circ} 1$ letra b) de la Ley en cuestión frente al fiscalizado que solicita copia, supone que "la carga de la motivación aumenta a medida que pasa el tiempo desde que se llevó a cabo la fiscalización" 59 .

En conclusión, a mayor tiempo desde verificada la fiscalización, mayor es el deber de justificación o motivación para rechazar el acceso al expediente de fiscalización. Ahora bien, sin perjuicio de la mayor motivación que pueda tener la resolución de la SMA que deniegue el acceso al expediente de fiscalización, se verifica de todas maneras el perjuicio para el administrado respecto a la producción de medios de prueba que acrediten su inocencia.

3.4. La posibilidad de la SMA de solicitar pericias probatorias posteriores a la formulación de cargos, sin contar con la obligación de otorgar traslado al fiscalizado ni de otorgar un plazo razonable para su respuesta

\footnotetext{
${ }^{56}$ STA2 $^{\circ}$, Rol R-13-2013, Considerando 6 ${ }^{\circ}$

${ }^{57}$ El referido precepto dispone "Las únicas causales de secreto o reserva en cuya virtud se podrá denegar total o parcialmente el acceso a la información, son las siguientes: 1. Cuando su publicidad, comunicación o conocimiento afecte el debido cumplimiento de las funciones del órgano requerido, particularmente: b) Tratándose de antecedentes o deliberaciones previas a la adopción de una resolución, medida o política, sin perjuicio que los fundamentos de aquéllas sean públicos una vez que sean adoptadas".

${ }^{58}$ Corresponde a los recursos de casación en la forma y fondo contra Sentencia del Tribunal Ambiental de Santiago en causa Rol-79-2015 de fecha 07.08.2017.

${ }_{59}^{5}$ Afirmación contenida en la misma sentencia.
} 
Esta situación va en desmedro del objetivo buscado por el legislador al establecer la obligación de la SMA de realizar una formulación concreta, clara y precisa de los hechos que estime constitutivos de infracción y de la normativa supuestamente infringida. Así, se puede verificar una especie de reformulación tácita de cargos, sin resultar exigible, por tanto, el otorgamiento de un nuevo plazo para presentar descargos con la respectiva imposibilidad de parte del administrado de aportar los medios de prueba que estime pertinente y solicitar las correspondientes diligencias probatorias pertinentes y conducentes.

En este sentido, la formulación de cargos juega un rol fundamental para que el presunto infractor pueda ejercer adecuadamente su derecho a defensa, ya que por medio de este acto se traba o fija el alcance técnico y jurídico de la discusión en sede administrativa.

En la misma línea, refiriendo al rol que juega la formulación de cargos, Osorio señala que este "fija el objeto del procedimiento administrativo sancionador e informa al presunto infractor cuál o cuáles son las infracciones administrativas por las que será procesado" (Osorio, 2016, p. 311). Agrega en este sentido que "la formulación de cargos viene a satisfacer el derecho del imputado a conocer la acusación administrativa al otorgarle todos los antecedentes que fundan la acusación. Lo anterior, permite que el presunto infractor pueda defenderse de las acusaciones o cargos formulados por la autoridad administrativa" (Osorio, 2016, p. 311).

Respecto a la importancia del plazo para responder los cargos formulados, la jurisprudencia ha sido clara en relación con la necesidad de otorgar plazos razonables para poder defenderse, de esta forma "los cargos deben concretarse y ponerse en conocimiento del imputado, con el objeto que proceda a contestarlos, para lo cual se concede un plazo razonable. Así se explica que el requerimiento deba considerar los aspectos de hecho y que guarde vinculación con el pronunciamiento del tribunal" ${ }^{\prime \prime}$.

Por su parte, la formulación de cargos, en cierta forma, fija el contenido no solo de la acusación sino del alcance de esta. Por lo tanto, agregar con posterioridad a la formulación de cargos información técnica esencial para justificar la procedencia de estos, en la práctica, transgrede el derecho a defensa del imputado al restringirse sustantivamente el tiempo de respuesta que aquel tiene para presentar descargos y limita las posibles líneas estratégicas que utilizar ${ }^{61}$. Todo lo anterior se traduce en una especie impropia de reformulación de cargos. Por su parte, una reformulación de cargos en ningún caso puede hacerse en desmedro de la posición del fiscalizado, no pudiendo utilizarse este método para subsanar errores, vicios o vacíos de los que adolecía la formulación original.

Por otro lado, permitiría a la SMA contar con nuevos antecedentes para desvirtuar lo planteado por el supuesto infractor en sus descargos, lo que produciría prueba a medida. Sobre ello, conviene tener presente lo afirmado por Dougnac respecto a que el procedimiento administrativo sancionador "se encuentra imbuido de una suerte de ad intentionem punire, respecto del cual el administrado no se encuentra en un plano de igualdad de armas con la Administración. Lo anterior tiene una serie de consecuencias sobre la aplicación de los principios del Debido Proceso, siendo a mi juicio la más relevante el que el derecho a defensa supone siempre una base inmutable de discusión, respecto de la cual deberá producirse la prueba. De lo contrario, resulta inoficioso la realización de descargos, ya que la Administración tendrá siempre la posibilidad de desestimarlos en el transcurso del Procedimiento Administrativo Sancionatorio mediante

60 SCS Rol 2578- 2012 de 07.09.2012.

${ }^{61}$ Una situación similar se verifica en la competencia otorgada al Superintendente del Medio Ambiente de ordenar la realización de nuevas diligencias luego de recibir el dictamen del instructor del procedimiento (Art. 54 de la LOSMA). 
la producción de nuevas diligencias probatorias ad hoc a los argumentos entregados por los formulados descargos" (Dougnac, 2016,) pp. 174-175).

Agrava lo anterior el hecho de que la SMA no se encuentra obligada por las reglas de la LOSMA a dar traslado al fiscalizado para que formule sus observaciones $^{62}$, y en aquellos casos que da traslado, habitualmente se otorga un plazo de respuesta ilusorio considerando la complejidad técnica que normalmente estas pericias tienen asociadas. Una muestra de esto puede apreciarse en lo dispuesto por el Tribunal Ambiental de Valdivia, el que refiriéndose a las dificultades del administrado para acceder a los antecedentes probatorios señaló que "el término para acceder a la documentación y formular observaciones fue de tres días, ampliado en dos días más (...) proporcionó plazos breves que no se condicen con la dificultad adicional de acceso a la prueba ya expresado"63.

3.5. Actos trámites que constituyen la base fáctica de la sanción no pueden ser impugnados

Ciertos actos trámite del procedimiento sancionatorio, como la formulación de cargos, la resolución que se pronuncia sobre la solicitud de medidas probatorias o la resolución que ordene la realización de nuevas diligencias por parte del Superintendente, constituyen una base fáctica extremadamente relevante para la decisión de la SMA y la determinación de la sanción.

Respecto a la relevancia de la base fáctica sobre la que se construye el acto administrativo y su posterior revisión judicial, se ha señalado que "si la ficción de validez incluye la verificación material de los antecedentes fácticos que han servido para la decisión administrativa, no se ve cómo es posible entender que esta no despliega esa fuerza en el ámbito judicial. No parece del todo razonable efectuar una separación tajante y absoluta entre lo que es efecto político o legitimador de un acto administrativo, y un efecto jurídico o probatorio" (Hunter, 2015, p. 657).

Como ya anotamos previamente, el control judicial no exime en ningún caso a la Administración de seguir un procedimiento administrativo racional y justo, tal como lo ha establecido el Tribunal Constitucional ${ }^{64}$.

Pese a que el artículo 56 de la LOSMA dispone que toda persona tiene el derecho a reclamar antes los tribunales ambientales cuando considere que una resolución de la SMA "no se ajustan a la ley, reglamentos o demás disposiciones", a criterio de la Corte Suprema se deben entender reclamables solo los actos terminales de la SMA ${ }^{65}$, excluyendo incluso aquellos actos trámite que causen indefensión, los que solo pueden ser revisados como parte o fundamento de una impugnación a la decisión final (Bordalí, 2017, p. 328).

Por su parte, conforme a lo dispuesto en el artículo 62 de la LOSMA, en todo lo no previsto en dicha ley se aplicará supletoriamente la LBPA, de lo que puede inferirse que resultarán aplicables a las resoluciones de la SMA, al menos el recurso de reposición (artículo 59 LBPA), el recurso extraordinario de revisión (artículo 61 LBPA) y la petición de aclaración (artículo 62 LBPA).

Considerando lo que se desarrollará más adelante respecto a las limitaciones probatorias propias del

\footnotetext{
${ }^{62}$ Aunque en la práctica, en ciertos casos la SMA sí ha dado traslado al administrado. A modo de ejemplo, ver proceso sancionatorio SMA Rol D-14-2015.

63 STA3 $^{\circ}$, Rol R-11-2015, de 04.08.2015, Considerandos $24^{\circ}$ y $25^{\circ}$.

64 STC Rol No 376 de 2013.

${ }^{65}$ En sentencia de 20 de septiembre de 2016, Rol № 5328-2016, el máximo tribunal dispuso en su considerando duodécimo que "conforme a las reflexiones que preceden, el Tercer Tribunal Ambiental de Valdivia, no debió admitir a tramitación la reclamación deducida de acuerdo al procedimiento contemplado en el artículo $17 \mathrm{~N}^{\circ} 3$ de la Ley № 20.600, en contra de una resolución que es de mero trámite y en consecuencia no reviste el carácter de terminal y, en concordancia con ello, tampoco pudo entre otras dictar sentencia definitiva rechazando la referida reclamación, por haberse deducido en contra de una resolución que por su naturaleza era inadmisible de impugnar por esta vía...".
} 
contencioso administrativo ambiental, el no poder impugnar de manera independiente los actos de mero trámite que causen indefensión (o incluso aquellos que sin causar indefensión desmejoran la situación jurídica del administrado) puede condicionar o limitar severamente el derecho a la defensa del supuesto infractor en la revisión judicial de la decisión administrativa.

A modo de ejemplo, la resolución que rechace la solicitud de la práctica de una diligencia probatoria testimonial se traducirá en definitiva en que dicha prueba no habrá sido rendida en el procedimiento administrativo ni podrá ser aportada en el proceso judicial de reclamación. Algo similar ocurrirá cuando la formulación de $\operatorname{cargos}^{66}$ adolece de precisión o claridad ${ }^{67}$, lo que limitaría seriamente la posibilidad de defenderse tanto de las infracciones mismas como de la gravedad imputada a ellas.

Habiendo ya explicado las deficiencias relativas al debido proceso presentes en el procedimiento administrativo sancionador contemplado en la LOSMA, en el siguiente acápite, junto con describir y explicar el control judicial llevado a cabo por los tribunales ambientales, se buscará identificar las carencias propias de esta instancia respecto al debido proceso principalmente asociadas a la limitación probatoria.

\section{Contencioso administrativo ambiental y sus limitaciones relativas al debido proceso}

\subsection{Control jurisdiccional de los actos administrativos}

De una manera esencial, el Estado de derecho descansa en la separación e independencia de los poderes del Estado a fin de asegurar las garantías constitucionales de los administrados (Bordalí, 2016, p. 17) siendo los tribunales de justicia los máximos garantes de la protección de los derechos de las personas.

Así, uno de los pilares esenciales del Estado de derecho consiste en que todas las personas tienen derecho a obtener una tutela judicial de cualquier interés legítimo o derecho subjetivo siendo particularmente relevante la impugnabilidad de los actos administrativos, configurado como un principio reconocido a nivel constitucional (artículos $19 \mathrm{~N}^{\circ} 3,38$ inciso $2^{\circ}$ y $73 \mathrm{CPR}$ ) y legal (artículo $8^{\circ}$ de la Ley N $N^{\circ} 18.575$ Orgánica Constitucional de Bases Generales de la Administración del Estado y artículo 15 de la LBPA).

Respecto al objetivo de lograr una tutela judicial de los intereses legítimos o derechos subjetivos por parte de la justicia administrativa, Ferrada explica en relación con nuestro modelo nacional que "la Constitución de 1980 hace una opción clara por un modelo subjetivo de justicia administrativa, donde el núcleo central está construido sobre la idea de la 'lesión de derechos', posición jurídica subjetiva desde la que debe erigirse el sistema de impugnación de los actos administrativos" (Ferrada, 2012, p. 116).

\footnotetext{
${ }^{66}$ Respecto a la imposibilidad de impugnar una formulación de cargos, ver SCS Rol N 18231-2017, № 43035-2017 y N $45556-2017$ ). ${ }^{67}$ En relación con la necesidad de que la formulación de cargos sea precisa y clara la Corte Suprema a dispuesto que "los cargos que se formulen por la autoridad deben ser concretos y precisos, debiendo necesariamente detallar los hechos constitutivos de las infracciones que se les atribuyen a los inculpados y la forma como ellos han afectado los deberes que establecen las normas legales, reglamentarias, técnicas o administrativas que se han vulnerado" SCS Rol N 822-2012, Considerando $27^{\circ}$.
} 
En este sentido, se ha señalado que "para la efectiva vigencia del Estado de Derecho, en su versión más moderna, ya no es tan relevante quien es el detentador de la potestad sancionadora, sino que el ejercicio de esta tenga garantizada una instancia judicial revisora ...la revisión judicial es la verdadera garantía del ciudadano frente al poder estatal y no la existencia de un procedimiento administrativo previo para el ejercicio de cualquier potestad administrativa" (Ferrada, 2014ª , p. 244).

En Chile, la Administración (en mayor medida que el legislador) ha sido reticente a sujetarse al control jurisdiccional mandatado en la CPR. Así lo explica Bordalí: "no ha sido el legislador el que se ha resistido mayormente a ser controlado por los tribunales de justicia, sino la Administración del Estado. Esta, arropada por el legislador y por la Corte Suprema y por el Tribunal Constitucional, ha evitado hasta hoy, con relativo éxito en muchos casos ser controlada por la jurisdicción" (Bordalí, 2006, p. 18).

Uno de los efectos de esta reticencia por parte de la Administración se expresa, en ciertos tipos de procedimientos en los que ella actúa, al menos de facto, como una primera instancia de control jurisdiccional reconociendo a los tribunales de justicia solo la facultad de realizar un control de su actuar como jueces de segunda instancia (Bordalí, 2006, p. 18).

Desde una dimensión subjetiva "la tutela judicial se traduce en un derecho fundamental: el derecho de acceso a la justicia, el cual debe ser respetado en su esencia por todos los órganos del Estado, incluido el poder legislativo. En este último caso, este respeto/deber se traduce en que la ley no puede establecer condiciones que afecten el libre ejercicio de este derecho, afectando su contenido esencial (artículo 19 № 26 CPR.)" (Cordero, 2014, p. 435).

Respecto al contenido mínimo del debido proceso ${ }^{68}$, la Corte Suprema ha dispuesto que "el catálogo de garantías mínimas para un proceso racional y justo implica siempre un procedimiento con la presencia de un contradictor y que las partes en el pleito tienen derecho a un trato en igualdad de condiciones, pero a la vez, importa realzar el indispensable análisis de toda la prueba rendida en autos"69.

\subsection{Acciones contencioso-administrativas}

Las acciones contencioso-administrativas han sido conceptualizadas por la doctrina como aquel "conjunto de acciones jurisdiccionales puestas a disposición de los administrados, con el objeto de impugnar la actuación de la Administración del Estado, conseguir la declaración de un derecho oponible a esta o la condena de la misma para que realice una actuación o entregue una prestación" (Bermúdez, 2011, p. 429).

De acuerdo con la distinción clásica del derecho francés (Bermúdez, 2011, p. 429), las acciones contenciosas administrativas pueden ser clasificadas en acciones de: (i) nulidad, (ii) de plena jurisdicción, (iii) de interpretación y (iv) contencioso de represión. Respecto a esta clasificación, en opinión de Bermúdez, las reclamaciones de sanciones administrativas se encontrarían contenidas en la categoría del contencioso de represión ${ }^{70}$, señalando al respecto que "el contencioso de la represión consiste en la posibilidad de reclamar de esta sanción ante el juez competente", agregando a reglón seguido que "la sanción administrativa debe quedar siempre bajo el control del juez" (Bermúdez, 2011, p. 434).

\footnotetext{
${ }^{68}$ En similar sentido se ha pronunciado el Tribunal Constitucional. Ver STC Rol № 821-2008.

69 SCS Rol No 7372-2010.

70 El mismo profesor Bermúdez anota que en el caso del derecho administrativo alemán, la calificación aplicable correspondería a la "acción impugnatoria o de anulación", entendiendo por tal "aquella que pretende la anulación de un acto administrativo de gravamen" (Bermúdez, 2011, p. 435).
} 
Solo con la revisión jurisdiccional de la sanción administrativa se puede lograr el aseguramiento del debido proceso al que tienen derecho las personas. En este sentido se ha pronunciado el Tribunal Constitucional al disponer "que si bien puede resultar lícito que los órganos fiscalizadores puedan, previo al proceso judicial y en el ámbito administrativo, determinar la existencia de una infracción y la cuantía de la multa, con lo que se pronuncia sobre la facultad fiscalizadora y sancionatoria, la sanción no puede estimarse como cierta e irrevocable por el ordenamiento jurídico sino una vez que no haya sido reclamada, o si habiendo sido reclamada esta ha sido fallada en sede jurisdiccional independiente"71.

De esta manera, solo en sede judicial el administrado puede encontrar un análisis imparcial, toda vez que no corresponde hablar de imparcialidad respecto de la Administración "debido a que siempre actúa como una idea de autotutela, es decir, decide asuntos en los que aparece interesada, pues debe lograr esos intereses generales que en sentido amplio los podemos entender como políticos. En cambio, la jurisdicción actúa como un tercero o con desinterés objetivo" (Bordalí y Hunter, 2017, p. 305). Así, en la jurisdicción solo se presenta un fin: aplicar el derecho en un caso concreto frente a una pretensión deducida por un sujeto interesado.

En este sentido, Cordero señala que "los jueces disponen de controles plenos de revisión de la legalidad de la intervención de los organismos administrativos, considerando incluso el escrutinio de los hechos sobre los cuales se basan esas decisiones, sencillamente porque esos hechos habitualmente condicionan el ejercicio de las potestades" (Cordero, 2015a, p. 634).

\subsection{Tipo de control en el contencioso administrativo}

Para determinar el nivel de control que pueden ejercer los tribunales sobre los actos administrativos impugnados, debe atenderse a la amplitud de los poderes que se le confieren al juez para conocer y fallar el litigio y, como consecuencia, la profundidad y extensión con que revisará el mismo.

Siguiendo la clasificación clásica del derecho francés, pueden identificarse dos tipos de acciones, aquellas (i) acciones por exceso de poder (anulatorias) y las (ii) de plena jurisdicción, categorías "que ponen el acento de la distinción en la amplitud y extensión de las facultades que se reconocen al juez para resolver en el litigio administrativo respectivo" (Jara, 2018, p. 74).

En la primera categoría, el juez se limita a revisar la actuación de la Administración, recurriendo a una especie de deferencia al principio de separación de poderes, acotándose a contrastar el acto con la ley, anulándolo en caso de no adecuarse a la norma, devolviendo luego el asunto a la Administración.

Por su parte, el control de plena jurisdicción, como su nombre lo indica, se configura como un control integral y profundo, en el que se le permite al juez extenderse a cualquier decisión que estime útil y necesaria para proteger la esfera subjetiva del reclamante afectado, respondiendo de esta forma a la idea de tutela subjetiva de los derechos e intereses del administrado y no solamente al restablecimiento de la legalidad infringida por razones de interés general (Jara, 2018, pp. 75-76). Este control de plena jurisdicción puede analizarse desde dos dimensiones: (i) su intensidad y (ii) su extensión.

En relación con la intensidad del control pleno, pueden verificarse diferentes niveles, siendo el más básico aquel que permite al juez revisar los hechos y calificarlos jurídicamente, avanzando luego a un estadio en el que se revisa incluso la apreciación de la proporcionalidad de la sanción impuesta (Jara, 2018, p. 78). La determinación del nivel de intensidad variará dependiendo del caso concreto, siendo la regla que a mayor afectación o gravedad de los bienes involucrados, más intenso y

${ }^{71}$ STC Rol № 792. 
amplio deberá ser el parámetro de control en función de la tutela de los derechos e intereses legítimos del sujeto afectado (Ferrada, 2014a, p. 249).

La extensión del control de plena jurisdicción se refiere a los ámbitos de la potestad administrativa sobre los que se puede realizar la revisión judicial y los medios o instrumentos de los que se puede valer el juez (Ferrada, 2014a, p. 251). Tradicionalmente se ha considerado parte de la extensión de este control la revisión de los hechos constitutivos de infracción, su existencia y su calificación jurídica, es decir, "la realidad de los antecedentes que sustentan la actuación punitiva adoptada por la entidad administrativa" (Jara, 2018, p. 77).

En el caso del control de las sanciones administrativas, la doctrina chilena se inclinaría por incorporarlo dentro de las acciones de plena jurisdicción (Valdivia, 2017), lo que correspondería a "la solución más compatible y coherente con el derecho a una tutela judicial efectiva y la exigencia del debido proceso en los términos que contemplan los artículos $19 N^{\circ} 3$ y 38 de la Constitución" (Jara, 2018, p. 79), lo que sería concordante con la tendencia en el derecho comparado a considerar la potestad sancionatoria como una de carácter reglado, con acotados espacios de discrecionalidad en lo estrictamente técnico, lo que permitiría el desarrollo de un control extensivo por parte de los tribunales (Ferrada, 2014a, p. 247).

Ahora bien, como se desarrollará en extenso a continuación, dado que el contencioso administrativo contemplado en la LTA recurre a las reglas de la apelación en materia civil, se restringe severamente el control efectivo de los tribunales ambientales respecto a las sanciones impuestas por la SMA al no existir una discusión real sobre los hechos y una severa limitación probatoria.

\subsection{Contencioso administrativo de la LTA}

Respecto al proceso de reclamación ante los tribunales ambientales, la Ley $N^{\circ} 20.600$ acoge un modelo de revisión de legalidad, que no permite la aportación de prueba, salvo la presentación de prueba documental. Así, el artículo 29 inciso $3^{\circ}$ hace aplicable las reglas del recurso de apelación civil contenidas en los artículos 186 a 230 del CPC, dentro de las cuales, el artículo 207 establece que no se admitirá en segunda instancia prueba alguna, salvo la documental (excepción contenida en el artículo $348)^{72}$.

En este sentido Santamaría Pastor señala que "la equiparación tácita del recurso contencioso con el recurso de casación civil conllevaba, entre otros efectos, que el Tribunal no podía pronunciarse sobre cuestiones que no hayan sido planteadas o resueltas en la vía administrativa previa; que en el proceso no podía practicarse más actividad probatoria que la dirigida a revisar la realizada en vía administrativa" (Santamaría, 2009, p. 687).

Cuando las sanciones son extremadamente graves, como se verifica en materia ambiental, resulta razonable considerar un control jurisdiccional de plena competencia para poder decidir sobre los hechos controvertidos y el derecho aplicable. Así, en esta instancia deberían poder revisarse todas las decisiones adoptadas en la fase administrativa, debiendo pronunciarse el juez solo respecto de lo que se alegue y se logre probar en esta instancia judicial.

En el sistema actual, los tribunales ambientales solo tienen la posibilidad de revisar la legalidad del acto administrativo recurrido, identificando solo posibles ilegalidades en el comportamiento de la Administración, dando por ciertos todos los elementos del expediente

\footnotetext{
${ }^{72}$ Sin perjuicio de lo anterior, el tribunal podrá, dentro del plazo para dictar sentencia, decretar medidas para mejor resolver (artículo 29 inciso final).
} 
administrativo, pieza que como vimos en capítulos anteriores puede contener una serie de distorsiones que en muchos casos puede generar situaciones de indefensión para el sancionado.

Solo en la fase judicial de revisión se podrá acceder a un proceso que asegure el debido proceso del administrado, esto es, someter la decisión de un caso ante un tercero imparcial, con un sistema de libre aportación probatoria, con una pretensión de espectro amplio planteada por el reclamante o recurrente.

Particular relevancia en este sentido adquiere el valor probatorio que se le otorga a la prueba aportada por la Administración y por el administrado en el proceso administrativo sancionador, lo que no debería ser considerado más que fuentes de prueba (Poblete, 2016, p. 35).

Al respecto debe necesariamente tener a la vista la garantía constitucional contemplada en el artículo $19 N^{\circ} 3$ CPR, el que sanciona en su inciso $1^{\circ}$ que "La Constitución asegura a todas las personas: $3^{\circ} \mathrm{La}$ igual protección de la Ley en el ejercicio de sus derechos". Relevante también para el análisis es el inciso segundo del precepto aludido el que dispone: "Toda persona tiene derecho a defensa jurídica en la forma que la ley señale y ninguna autoridad o individuo podrá impedir, restringir o perturbar la debida intervención del letrado si hubiere sido requerida".
En este sentido, se ha señalado doctrinalmente que los elementos mínimos de un debido proceso corresponden al (i) derecho a un tribunal competente, independiente e imparcial, (ii) el derecho a la defensa, (iii) el derecho a aportar pruebas, (iv) a contar con una sentencia debidamente fundamentada y dentro de un plazo razonable ${ }^{73}$.

Con la entrada en vigor de la LTA, se crea un contencioso administrativo especializado ${ }^{74}$, el que pone como principal objetivo la protección de los derechos individuales de las personas frente a la Administración (Hunter, 2015, p. 649).

Son los tribunales ambientales ${ }^{75}$ los competentes para conocer de los contenciosos administrativos de carácter ambiental por medio del procedimiento contemplado en los artículos 27 a 31 LTA, denominado "De las Reclamaciones", por el que se busca revisar la legalidad de los actos administrativos de carácter ambiental.

Respecto al alcance de la revisión judicial realizada por los tribunales ambientales, en opinión de Bordalí, estos realizarían una revisión plena de los actos administrativos impugnados, abarcando no solo los fundamentos de derecho sino también las cuestiones de hecho tenidas a la vista por la Administración (Bordalí, 2017, p. 232). Sostiene lo anterior fundado, por un lado, en la exigencia del artículo 29 de la LOSMA de acompañar el expediente

\footnotetext{
${ }^{73}$ Ver Bordalí, A. (2014). Primera parte: Cuestiones preliminares. En A. Bordalí, A. Cortez y G. Palomo. Proceso civil el juicio ordinario de mayor cuantía, procedimiento sumario y tutela cautelar. Santiago: Abeledo Perrot / Legal Publishing / Thomson Reuters, pág. 37.

${ }^{74}$ En opinión de Bordalí, no existiría en Chile una jurisdicción en materia ambiental especializada, toda vez que "solo una parcela de los conflictos ambientales es competencia de los tribunales ambientales o solo algunos grados jurisdiccionales son conocidos por ellos, correspondiendo la segunda instancia o la casación a tribunales ordinarios como las Cortes de Apelaciones o la Corte Suprema" (Bordalí, 2014b, p. 331).

${ }^{75}$ Conforme al artículo $1^{\circ}$ de la LTA, los tribunales ambientales corresponden a órganos jurisdiccionales especiales, sujetos a la superintendencia directiva, correccional y económica de la Corte Suprema (por lo que deben entenderse fuera el Poder Judicial). Por su parte gozan de inamovilidad (artículo $5^{\circ} \mathrm{LTA}$ ) y de independencia respecto de la Administración (sustentada, entre otras características, en contar con un presupuesto propio (artículo 16 de la LTA). En opinión de Bordalí, la referida independencia se ve fuertemente atenuada por la alta injerencia que tiene el Poder Ejecutivo en la nominación de los ministros, al presentar una "doble participación en la nominación de los ministros (Alta Dirección Pública y Presidente de la República, lo que se contrapone a las recomendaciones internacionales sobre nominaciones de jueces, que recomiendan aminorar al máximo la participación del Poder Ejecutivo en la nominación de los jueces" (Bordalí, 2014b, pp. 330-331). Respecto a la relevancia de la independencia de los tribunales de justicia, ver Bordalí (2006) pp. 33-34.
} 
administrativo completo para que el tribunal pueda realizar una revisión de todas las cuestiones fácticas y jurídicas del caso y, por otro, en lo prescrito en el artículo 25 del mismo cuerpo normativo que dispone que el tribunal ambiental deberá exponer en sus sentencias los principios técnicos ambientales que le sirvieron de fundamento.

En materia ambiental, más que una falta de control jurisdiccional, lo que se propone como tesis es que dicho control resulta insuficiente, al menos respecto de las sanciones de mayor envergadura que puede imponer la SMA, particularmente, la imposición de multas millonarias, la suspensión de proyectos y la revocación de resoluciones de calificación ambiental.

\subsection{La prueba en el contencioso ambiental}

\subsubsection{Regulación de la prueba en las reclamaciones} ambientales

La prueba que contempla el procedimiento de reclamación en contra de resoluciones de la SMA ante el TA (artículo 29 LTA) hace aplicable las reglas del recurso de apelación civil contenidas en los artículos 186 y 230 del CPC. De estas, solo el artículo 207 se refiere a la prueba indicando que, salvo excepciones como la del artículo 348 (prueba documental), no se admitirá en segunda instancia prueba alguna.
En el fondo, el contencioso ambiental no contempla formalmente un término probatorio en el que se les permita a las partes probar sus dichos, situación que se ve agravada por la connatural complejidad técnica propia de los conflictos ambientales.

Esta carencia de una fase probatoria impide catalogar este proceso en un auténtico proceso contradictorio, lo necesariamente repercute en el aseguramiento de la garantía constitucional del debido proceso. Esta situación se agrava si lo que se pretende objetar corresponde a sanciones administrativas, toda vez que estas "adoptan una base fáctica ineludible y de gran complejidad técnica, de modo que la configuración del derecho a la prueba oportuna y eficaz en el diseño de dichas acciones especiales constituye parte esencial de la vigencia de un verdadero proceso equitativo y de contradictorio pleno e idóneo" (Jara, 2018, p. 69).

Sin establecer explícitamente la forma en que el reclamante puede aportar la prueba ${ }^{76}$, la LTA se limita a requerir un informe al órgano público que emitió el acto reclamado, junto con la obligación de acompañar una copia completa, autentificada y foliada del expediente administrativo que sirvió de base para la dictación del acto administrativo impugnado ${ }^{77}$, para luego disponer que una vez presentado el informe, o habiendo transcurrido

\footnotetext{
${ }^{73}$ Ver Bordalí, A. (2014). Primera parte: Cuestiones preliminares. En A. Bordalí, A. Cortez y G. Palomo. Proceso civil el juicio ordinario de mayor cuantía, procedimiento sumario y tutela cautelar. Santiago: Abeledo Perrot / Legal Publishing / Thomson Reuters, pág. 37.

${ }^{74}$ En opinión de Bordalí, no existiría en Chile una jurisdicción en materia ambiental especializada, toda vez que "solo una parcela de los conflictos ambientales es competencia de los tribunales ambientales o solo algunos grados jurisdiccionales son conocidos por ellos, correspondiendo la segunda instancia o la casación a tribunales ordinarios como las Cortes de Apelaciones o la Corte Suprema" (Bordalí, 2014b, p. 331).

${ }^{75}$ Conforme al artículo $1^{\circ}$ de la LTA, los tribunales ambientales corresponden a órganos jurisdiccionales especiales, sujetos a la superintendencia directiva, correccional y económica de la Corte Suprema (por lo que deben entenderse fuera el Poder Judicial). Por su parte gozan de inamovilidad (artículo $5^{\circ}$ LTA) y de independencia respecto de la Administración (sustentada, entre otras características, en contar con un presupuesto propio (artículo 16 de la LTA). En opinión de Bordalí, la referida independencia se ve fuertemente atenuada por la alta injerencia que tiene el Poder Ejecutivo en la nominación de los ministros, al presentar una "doble participación en la nominación de los ministros (Alta Dirección Pública y Presidente de la República, lo que se contrapone a las recomendaciones internacionales sobre nominaciones de jueces, que recomiendan aminorar al máximo la participación del Poder Ejecutivo en la nominación de los jueces" (Bordalí, 2014b, pp. 330-331). Respecto a la relevancia de la independencia de los tribunales de justicia, ver Bordalí (2006) pp. 33-34.

${ }^{76}$ El artículo 29 inciso $3^{\circ}$ LTA dispone la inadmisibilidad probatoria testimonial y confesional.

${ }^{77}$ Respecto a la integralidad y unidad del expediente administrativo sancionatorio, el Tribunal Ambiental de Valdivia, en causa Rol-11-2015 de fecha 04.08.2015, ha señalado que "lo adecuado en materia de expediente sancionador, es que éste se contenga en una sola unidad, sea en soporte físico o digital, y que éste se encuentre a disposición de los interesados en las dependencias o bajo custodia de la unidad administrativa que lleva la investigación, de manera que los interesados tengan acceso real a los antecedentes que obran en su contra, especialmente porque sobre aquellos pesa la imposición de una sanción".
} 
el plazo para hacerlo, el tribunal debe ordenar traer los autos en relación ${ }^{78}$.

Conviene detenernos en el valor probatorio que se le debe entregar al expediente administrativo en su condición de "documento oficial". Al respecto, se puede señalar que el referido expediente solo debería hacer prueba sobre la fecha de su emisión, la participación de uno o más funcionarios públicos, la decisión de la Administración y la motivación para alcanzarla ${ }^{79}$.

En este sentido, seguimos a Poblete cuando señala que "los supuestos fácticos que sirven de fundamento a la decisión del funcionario, las conductas e hipótesis de hecho esgrimidas para la adopción de la decisión contenida en el documento oficial, no pueden probarse por el documento oficial en un proceso jurisdiccional". Agrega en la misma línea que "en estos documentos oficiales su contenido de declaraciones de terceros, actas y otras evidencias, no son prueba documental oficial. Tales evidencias no son constitutivas de prueba documental porque no son por naturaleza documentos" (Poblete, 2016, p. 35).

De esta manera debería concluirse que aquello que tuvo a la vista la Administración para motivar su decisión no puede, directamente al menos, ser utilizada en la instancia de revisión judicial (Poblete, 2016, p.36).

4.5.2. La carga de la prueba y su distribución en el contencioso ambiental

La carga de la prueba puede ser conceptualizada o definida como aquella regla de conducta para las partes, en cuanto su interés particular en la demostración de un hecho determinado por un lado, y como regla de juicio para el juez respecto a la forma de fallar el asunto a falta de prueba (Poblete, 2016, p. 42).
Para la determinación de la carga de la prueba en un tipo de proceso judicial determinado, debe necesariamente estarse al objeto que dicho proceso tiene. En el caso del contencioso administrativo sancionatorio, el objeto corresponderá a la reclamación o apelación que realice el administrado por medio del cual se cuestiona la procedencia, legalidad y entidad de la sanción impuesta, concentrándose habitualmente en la inexistencia (o inexactitud) de los supuestos fácticos sobre los que se construye la sanción y en la carencia de culpa o dolo del reclamante.

En este sentido, lo propio de las reclamaciones que se generan con motivo de un contencioso sancionador será "la afirmación de hechos negativos que deslegitiman absolutamente el ejercicio de la potestad sancionatoria, la aplicación de la sanción, la imposición de la sanción y la desproporción de esta" (Poblete, 2016, p. 43). Resulta razonable, entonces, que el reclamante en un contencioso administrativo sancionatorio solo tenga la carga de probar aquellos hechos o circunstancias favorables a su pretensión, no pudiendo imponérsele la prueba negativa de acreditar no haber cometido el hecho que se la imputa (Poblete, 2016, p. 57).

Este criterio ha sido refrendado por la Corte Suprema la que refiriéndose a la imposición de sanciones en materia eléctrica ha señalado que "Atendida la naturaleza, características y fines propios del derecho administrativo sancionador, recae sobre la autoridad que investiga y acusa, esto es sobre el órgano fiscalizador, el peso de demostrar la ocurrencia de los hechos que configuran la infracción respectiva [...] la carga probatoria que recae sobre el administrado [...] se refiere, a su turno, a la acreditación de aquellas circunstancias alegadas en su defensa y conforme a las cuales, a su juicio, se eximiría de la responsabilidad que le achaca la autoridad"80.

\footnotetext{
${ }^{78}$ El inciso final del mismo artículo 29 señala que solo dentro del plazo para dictar sentencia (30 días), se podrán dictar de oficio medidas para mejor resolver. Como la ley no señala cuáles pueden ser estas, resulta necesario remitirse al artículo 159 del Código de Procedimiento Civil.

${ }^{79}$ De esta manera, los documentos públicos (en este caso el expediente administrativo) se podrán presumir válidos, pero dicha presunción no debería alcanzar la veracidad de los contenidos probatorios de ellos.

80 SCS Rol No 19058-2017.
} 


\section{Felipe Arévalo Cordero}

Considerando que el ejercicio de la potestad sancionatoria por parte de la Administración es uno de los aspectos más relevantes (y eficaces) de la implementación de las políticas públicas como miras al aseguramiento de los intereses generales, resulta razonable que sea la propia Administración la más interesada en que los tribunales de justicia validen la legalidad de sus decisiones.

A diferencia de la actividad fiscalizadora sancionadora de la Administración, en la que de manera primaria se busca la protección de los intereses colectivos (respetando los derechos subjetivos de los particulares), la revisión judicial debe siempre orientarse a la protección de las garantías individuales de las personas, prescindiendo del interés general que el acto administrativo impugnado pretendía alcanzar (Cordero, 2015b, pp. 320-322).

En el caso específico de la LTA, no se regula expresamente la carga de la prueba, lo que "genera incerteza en los ciudadanos que recurren a la tutela jurisdiccional, al abrir la posibilidad de que los Tribunales utilicen criterios disímiles u opuestos en la asignación de la carga de la prueba para un idéntico supuesto fáctico" (Hunter, 2015, p. 650).

Matizando lo recién expuesto, recurriendo al criterio de disponibilidad probatoria ${ }^{81}$, Hunter señala que en el caso del contencioso ambiental "el interés público se satisface de mejor forma cuando el Tribunal Ambiental logra un conocimiento cabal y completo de los hechos, sin dudas epistémicas acerca de la verdad o falsedad de un hecho. Si esto es así, entonces la carga de la prueba en el contencioso administrativo ambiental debería recaer en aquél sujeto o parte que está en mejores condiciones de proporcionar información más completa y fiable posible" (Hunter, 2015, p. 654).

Complementando lo anterior, Bocksang explica que "en lo que al contencioso de los actos pretendidos que imponen una sanción se refiere, la constatación es simple: no se exige al demandante - sancionadoque contribuya con la prueba de no haber cometido el hecho que se imputa. Se trata de una carga que le incumbe normalmente a la autoridad que persigue dicha conducta; por el contrario, las circunstancias favorables a la persona perseguida deben ser probadas por ella" (Bocksang, 2011, p. 231).

De esta manera, cabe preguntarse sobre quién recae el peso de no lograr acreditar las alegaciones en el contencioso administrativo. Como ya se señaló, la LTA no se pronuncia expresamente respecto de la carga de la prueba, sin perjuicio de lo cual, considerando la inexistencia del término probatorio, y de la estructura del proceso, puede inferirse que en ausencia de la identificación de un vicio de legalidad dentro del expediente administrativo sobre el que se fundamentó el acto administrativo reclamado, se confirmaría la legalidad del acto radicando, de esta manera, en el administrado el peso de no lograr probar sus alegaciones. Esta estructura procesal evidentemente "sitúa al reclamante en una posición desventajosa y en esta realidad lo que corresponde jurídicamente es aliviarla imponiendo la carga de probar a la Administración sancionadora que es quien tiene una posición privilegiada con relación al material probatorio" (Poblete, 2016, p. 53).

\footnotetext{
${ }^{81}$ Que implicaría que es la contraparte la que posee el medio probatorio o, aun cuando la parte goce de medios probatorios, estos tienen menor entidad probatoria que los que únicamente dependen de la voluntad de la otra.
} 


\section{Conclusiones}

De lo expuesto a lo largo de este trabajo, es posible formular las siguientes conclusiones relevantes:

1. La naturaleza e importancia propia del medio ambiente como bien jurídico en sí mismo justifica la necesidad de que el ordenamiento jurídico cuente con herramientas que permitan darle una protección oportuna y efectiva.

2. Resulta razonable sostener que la existencia e implementación de las herramientas de amparo al medio ambiente establecidas por el legislador, no debiesen impedir en lo absoluto el derecho del regulado de contar con un debido proceso (administrativo y judicial) para el aseguramiento de sus derechos.

3. El procedimiento sancionatorio ambiental regulado en la LOSMA corresponde innegablemente a un gran avance en muchos sentidos del derecho administrativo sancionador chileno, particularmente respecto a la protección del derecho al debido proceso.

4. Sin perjuicio de estos grandes avances, en nuestra opinión, persisten serias carencias o deficiencias relevantes para el aseguramiento del debido proceso, dentro de las cuales se encuentran:

a. el valor probatorio privilegiado que le otorga la LOSMA al acta de fiscalización, considerando las limitaciones probatorias existentes en el procedimiento sancionatorio;

b. la excesiva desproporción existente entre el período de tiempo con que cuenta la SMA para preparar su caso (3 años) y el que cuenta el fiscalizado para presentar sus descargos, defensas y solicitar medidas probatorias (15 días);

c. las restricciones existentes para acceder a los expedientes de fiscalización previo a la formulación de cargos; d. la facultad de la SMA de decretar pericias probatorias posteriores a la formulación de cargos, pudiendo modificar de manera impropia el contenido técnico y jurídico de la acusación original y autogenerarse prueba a medida; $y$

e. la imposibilidad de impugnar actos trámites que determinan sustantivamente la base fáctica de la sanción, lo que puede condicionar severamente el derecho a defensa considerando las evidentes limitaciones probatorias en el control judicial posterior.

5. Solo con la revisión jurisdiccional de la sanción administrativa se puede asegurar el derecho de las personas a un debido proceso, lográndose adecuadamente dicho cometido cuando el referido control corresponde a uno de plena jurisdicción, en el que el juez puede revisar todas las decisiones adoptadas en la fase administrativa, debiendo pronunciarse solo teniendo en consideración aquello que sea alegado y efectivamente logrado probar en sede judicial.

6. En el caso específico del control jurisdiccional de las sanciones administrativas, la aplicación de las reglas del recurso de apelación civil restringe severamente el control efectivo de los tribunales ambientales al no contemplar instancias de discusión real sobre la base fácticas de las sanciones ni permitir más actividad probatoria que aquella tendiente a revisar la ya practicada en sede administrativa.

7. El contencioso ambiental no contempla formalmente un término probatorio en el que se les permita a las partes probar sus dichos, situación que se ve agravada por la connatural complejidad técnica propia de los conflictos ambientales.

8. Las carencias $\mathrm{O}$ debilidades vinculadas al aseguramiento del debido proceso previamente 
señaladas se ven potenciadas y agravadas si se considera que las sanciones en materia ambiental en la mayoría de los casos escapan de la mera corrección regulatoria, pudiendo ser consideradas penas propiamente tales, situación que exige contar con el control judicial más completo y profundo que sea posible.

\section{Referencias}

Aguirrezabal, M. (2016). Las medidas cautelares innovativas en la nueva institucionalidad medioambiental. Revista de Derecho, Universidad Católica del Norte, Año 23(1), 23-49.

Alcalde, E. (2009). Algunas consideraciones en torno a la identidad sustancial entre la sanción penal y la pena administrativa.

En J. Arancibia y J. I. Martínez (Coords.). La primacía de la persona: Estudios en homenaje al profesor Eduardo Soto Kloss, pp. 795-808. Santiago: Editorial Legal Publishing.

Arancibia, J. (2014). El principio de necesidad de la sanción administrativa como potestad de ultima ratio. En J. Arancibia

y P. Alarcón (Coords.). Sanciones Administrativas X Jornadas de Derecho Administrativo,pp. 129-147. Santiago: Editorial Thomson Reuters.

Arévalo, F. y Mozó, M. (2017). Efectos jurídicos de la declaración de daño ambiental en sede administrativa y sus repercusiones en una potencial declaración judicial. Actualidad Jurídica Uría Menéndez (46), 56-68.

Bermúdez, J. (2011). Derecho administrativo general ( $2^{\mathrm{a}}$ ed.). Santiago: Editorial Thomson Reuters.

Bermúdez, J. (2013). Fundamento y límites de la potestad sancionadora administrativa en materia ambiental. Revista de derecho Valparaíso (40), 421-447.

Bermúdez, J. (2014). Fundamentos de Derecho Ambiental ( $2^{\mathrm{a}}$ ed.). Valparaíso: Ediciones Universitarias de Valparaíso.

Bocksang, G. (2011). La carga de la prueba de la nulidad de un acto administrativo. En J. Arancibia, J. I. Martínez y A.

Romero (Coords.). Litigación Pública, pp. 217-244. Santiago: Editorial Abeledo Perrot.

Bordalí, A. (2006). La administración pública ante los tribunales de justicia chilenos. Revista Chilena de Derecho, 33(1), 17-36.

Bordalí, A., Ferrada, J. C. (2008). Estudios de justicia administrativa. Santiago: Editorial LexisNexis.

Bordalí, A., Cortez, G. y Palomo, D. (2014a). Proceso civil el juicio ordinario de mayor cuantía, procedimiento sumario y tutela cautelar. Santiago: Abeledo Perrot, Legal Publishing y Thomson Reuters.

Bordalí, A. (2014b). Recurso de protección y reclamos ante los Tribunales Ambientales. En J. C. Ferrada, J. Bermúdez y F. Pinilla (Coords.). La nueva justicia ambiental, pp. 329-341. Santiago: Thomson Reuters y Legal Publishing.

Bordalí, A. y Hunter, I. (2017). Contencioso Administrativo Ambiental. Santiago: Editorial Librotecnia.

Cordero, E. (2013). La nulidad de los actos administrativos en el Derecho Chileno. En J. C. Ferrada (Coord.) La nulidad de los actos administrativos y sus causales, pp. 193-203. Santiago: Editorial Legal Publishing.

Cordero, E. (2014). Los principios que rigen la potestad sancionadora de la Administración en el derecho chileno.

Revista de Derecho de la Pontificia Universidad Católica de Valparaíso (XLII), 399-439.

Cordero, E. (2017). El debido procedimiento administrativo sancionador y el derecho a la defensa. Sentencias Destacadas, pp. 67-96. Santiago: Libertad y Desarrollo.

Cordero, L. (2015a). Lecciones de derecho administrativo. Santiago: Editorial Legal Publishing.

Cordero, L. (2015b). Procedimiento administrativo y la jurisdicción contencioso administrativa. En J. C. Ferrada (Coord.). Justicia Administrativa, pp. 320-322. Santiago: Editorial LexisNexis.

Corral, H. (2012). Sobre la carga de la prueba en el proyecto de Código Procesal Civil. En M. Aguirrezabal. Justicia 
Civil: perspectivas para una reforma en la legislación chilena. Cuadernos de Extensión No 23, pp. 107-117. Santiago: Universidad de los Andes.

Dougnac, C. (2016). Procedimiento Administrativo Sancionatorio ante la SVS y debido proceso. Revista de Derecho Iberoamericano, (8), 143-186.

Fermandois, A. (2005). Invalidación Administrativa y caso Celco: estabilidad o precariedad de los permisos ambientales. Sentencias Destacadas, pp. 9-30. Santiago: Libertad y Desarrollo.

Ferrada, J. C. (2007). Las potestades y privilegios de la administración pública en el régimen administrativo chileno. Revista de Derecho (Valdivia), 20(2), 69-94.

Ferrada, J. C. (2012). El sistema de justicia administrativa chileno: revisión de la legalidad de actos administrativos o protección de derechos y/o intereses. Revista de Derecho (Valdivia), 25(1), 103-126.

Ferrada, J. C. (2014a). La articulación de las potestades administrativas y jurisdiccionales en la aplicación de sanciones administrativas en el derecho chileno: poderes distintos pero complementarios. En J. Arancibia, J. Alarcón y P. Jaña (Coords.). Sanciones administrativas, X Jornadas de Derecho Administrativo, pp. 239-262. Santiago: Abeledo Perrot, Legal Publishing y Thomson Reuters.

Ferrada, J. C. (2014b). La justicia ambiental como justicia administrativa especializada y su articulación con los procesos administrativos. En J. C. Ferrada, J. Bermúdez y F. Pinilla (Coords.). La nueva justicia ambiental, pp. 329-341. Santiago: Thomson Reuters y Legal Publishing.

Gutiérrez, P. (1999). La tutela jurisdiccional de los intereses supraindividuales: colectivos y difusos. Navarra: Editorial Aranzadi.

Hunter, I. (2015). La carga de la Prueba en el Contencioso Ambiental Chileno: Notas a propósito de la Ley de Tribunales Ambientales. Revista Chilena de Derecho, 42(2), 649-669.

Hunter, I. (2016). Es la presunción de legalidad de los actos administrativos una regla de carga de la prueba. En J. Arancibia y A. Romero (Coords.). La prueba en la litigación pública, pp. 211-232. Santiago: Editorial Librotecnia.

Hunter, I. (2020a). Relaciones entre procedimiento administrativo y proceso jurisdiccional en el reclamo de ilegalidad municipal. Revista de derecho, Coquimbo, 27, https://dx.doi.org/10.22199/issn.0718-9753-2020-0009

Hunter, I. (2020b). Legalidad y Oportunidad en el ejercicio de la potestad sancionatoria en materia ambiental. Revista de Derecho de la Pontificia Universidad Católica de Valparaíso (LIV), 95-125.

Jara, J. (2018). La revisión jurisdiccional de las sanciones administrativas y la garantía del recurso de plena jurisdicción. Revista de Derecho Público, Universidad de Chile, (89), 59-91.

Jara, J. y Maturana, C. (2009). Acta de fiscalización y debido procedimiento administrativo. Revista de Derecho Administrativo, (3), 01-28.

Letelier, R. (2018). El predio del statu quo. Sobre el estándar probatorio en las sanciones administrativas. Revista de Derecho (Valdivia), 31(1), 209-229.

Moraga, P. y Fuentes, M. (2017). Columna de opinión Sentencia Rol № 41.790 - 2016 de la Corte Suprema, de 7 de agosto de 2017. Revista Actualidad Jurídica Ambiental, Centro Internacional de Estudios de Derecho Ambiental. Recuperado de: http://derecho.uchile.cl/centro-de-derecho-ambiental/columnas-de-opinion/sentencia-rol-n-417902016-de-la-corte-suprema-07-08-2017 [fecha de consulta: 17 de octubre de 2020].

Navarro, E. (2011). El debido proceso en la jurisprudencia del Tribunal Constitucional. En En J. Arancibia, J. I. Martínez y A. Romero (Coords.). Litigación Pública, pp. 11-36. Santiago: Editorial Abeledo Perrot.

Nieto, A. (1994). Derecho Administrativo sancionador (2a ed.). Madrid: Editorial Tecnos.

Ortiz, E. y Pecchi, C. (1979). Concepto de documentos fundantes. Revista de Derecho de la Universidad de Concepción, (167), 67-81.

Osorio, C. (2016). Manual de Procedimiento Administrativo Sancionador: Parte General. Santiago: Editorial Legal Publishing Chile. 


\section{Felipe Arévalo Cordero}

Parejo, L. (2008). Crisis y renovación en el derecho público. Lima: Editorial Palestra.

Parejo, L. (2014). Algunas reflexiones sobre la necesidad de la depuración del status de la sanción administrativa.

Revista General de Derecho Administrativo, 36, 1-26.

Poblete, O. (2016). Procedimiento administrativo sancionador y enjuiciamiento posterior en la administración. En J. Arancibia y A. Romero (Coords.). La prueba de la litigación pública, pp. 15-82. Santiago: Editorial Librotecnia.

Román, C. (2008). Derecho administrativo sancionador: ¿Ser o no ser? He ahí el dilema. En R. Pantoja (Coord.). Derecho Administrativo: 120 años de Cátedra, 107-141. Santiago: Editorial Jurídica de Chile.

Romero, A. (2016). Algunos problemas del derecho al recurso en el contencioso ambiental. En J. Tisné (Ed). Cuadernos de Extensión Jurídica 28, pp. 209-222. Santiago: Universidad de los Andes.

Santamaría, J. (2009). Principios de Derecho Administrativo General, Tomo II. Madrid: Editorial lustel.

Sepúlveda, D. (2019). La modificación de la normativa ambiental aplicable a un proyecto que cuenta con una resolución de calificación ambiental. Revista de Derecho Aplicado LLM UC 3. DOI: 10.7764/rda.0.3.1121 [fecha de consulta: 17 de octubre de 2020].

Superintendencia del Medio Ambiente. (2017). Bases Metodológicas para la determinación de sanciones ambientales, diciembre. Santiago, Chile.

Valdivia, J. M. (2017). Reflexiones sobre las acciones en derecho administrativo. En A. Schopf y J. C. Marín (Coords.). Libro homenaje al profesor Enrique Barros, pp. 349-431. Santiago: Editorial Thomson Reuters.

\section{Jurisprudencia}

Corte Suprema, Rol No 7372-2010, de 07.03.2011.

Corte Suprema, Rol № 2578-2012, de 07.09.2012.

Corte Suprema, Rol No 5120-2016, de 05.05.2016.

Corte Suprema, Rol No 5328-2016, de 20.09.2016.

Corte Suprema, Rol № 17.736-2016, de 13.12.2016.

Corte Suprema, Rol No 38.340-2016, de 03.08.2017

Corte Suprema, Rol No 41.790-2016, de 07.08.2017

Corte Suprema, Rol No 19.058-2017, de 23.08.2017

Segundo Tribunal Ambiental, Rol D-24-2014, de 21.09.2014

Segundo Tribunal Ambiental, Rol D-6-2013, de 29.11.2014

Segundo Tribunal Ambiental, Rol R-122-2016, de 30.03.2017

Tercer Tribunal Ambiental, Rol R-11-2015, de 04.08.2015

Tribunal Constitucional, Rol No 712, de 26.06.2008

Tribunal Constitucional, Rol No 792, de 03.01.2008.

Tribunal Constitucional, Rol N821, de 01.04.2008.

Tribunal Constitucional, Rol No 1518, de 21.10.2010.

Tribunal Constitucional, Rol № 376, de 17.06.2013

Tribunal Constitucional, Rol № 2.682, de 30.10.2014 